University of San Diego

Digital USD

2019-5

\title{
Older Adults' Implementation of Discharge Instructions Following an Acute Care Hospital Stay
}

Brenda Miller

University of San Diego

Follow this and additional works at: https://digital.sandiego.edu/dissertations

Part of the Geriatric Nursing Commons

\section{Digital USD Citation}

Miller, Brenda, "Older Adults' Implementation of Discharge Instructions Following an Acute Care Hospital Stay" (2019). Dissertations. 157.

https://digital.sandiego.edu/dissertations/157

This Dissertation: Open Access is brought to you for free and open access by the Theses and Dissertations at Digital USD. It has been accepted for inclusion in Dissertations by an authorized administrator of Digital USD. For more information, please contact digital@sandiego.edu. 


\author{
UNIVERSITY OF SAN DIEGO \\ Hahn School of Nursing and Health Science \\ Beyster Institute for Nursing Research
}

DOCTOR OF PHILOSOPHY IN NURSING

\author{
Older Adults’ Implementation \\ of Discharge Instructions Following an Acute Care Hospital Stay \\ by \\ Brenda Miller, Ph. D., RN, PHN \\ A dissertation presentation to the \\ FACULTY OF THE HAHN SCHOOL OF NURSING AND HEALTH SCIENCE \\ UNIVERSITY OF SAN DIEGO \\ In partial fulfillment of the requirements for the degree \\ DOCTOR OF PHILOSOPHY IN NURSING
}

May 2019

\title{
DISSERTATION COMMITTEE
}

Ann Mayo, DNSc, RN, FAAN, Chairperson

Jane Georges, PhD, RN

Caroline Etland, PhD, RN 


\section{UNIVERSITY OF SAN DIEGO}

Hahn School of Nursing and Health Science

Beyster Institute for Nursing Research

DOCTOR OF PHILOSOPHY IN NURSING

CANDIDATE'S

NAME: $\quad$ Brenda Miller, RN, $\mathrm{PHN}, \mathrm{PhD}(\mathrm{c})$

TITLE OF

DISSERTATION: Older Adults' and Informal Caregivers' Implementation of

Discharge Instructions Following an Acute Care Hospital Stay

\section{DISSERTATION}

COMMITTEE:

Ann M. Mayo, DNSc, RN, FAAN

Chairperson

Jane Georges, PhD, RN

Committee Member

Caroline Etland, PhD, RN

Committee Member 


\begin{abstract}
Discharge instructions are a self-care guide for patients after discharge from an acute care hospitalization. The discharge process starts on admission to the hospital and continues until discharged. Many patients rely on informal caregivers to provide support after a discharge. However, it is often unclear whether the patients or caregivers completely understand instructions provided during the discharge process. Key concepts related to how discharge instructions were implemented following discharge to home have been understudied from the patient's and informal caregivers' perspectives. Developing effective discharge instructions based on study findings may assist in reducing 30-day hospital readmission rates.
\end{abstract}

This study was intended to explore how older adult patients (age 65 years and older) and their informal caregivers implemented discharge instructions following discharge. A qualitative methodology was used to conduct this study.

The primary aims of this study were to:

1. Describe how discharge instructions were implemented in the home setting by adults 65 years of age and older and their caregivers following an acute care hospital discharge.

2. Identify perceived facilitators and barriers to implementation of discharge instructions among older patients and their informal caregivers.

In-depth, semi-structured interviews were conducted with older adults and their informal caregivers within seven days of discharge from an acute care facility. This grounded theory study used an emergent qualitative paradigm, specifically social constructivist grounded theory. Emergent methods were appropriate for a study designed 
to bring emerging properties of an understudied phenomenon to light. Interviews were recorded and transcribed by a professional transcriptionist. In keeping with social constructivist grounded theory, constant comparative data analysis was conducted as the interviews were completed.

Study results demonstrated that participants knew they have been given discharge instructions, but once home the discharge instructions were not necessarily followed. Three study themes emerged and included a) Transitioning Hospital to Home Process, b) Knowing Their Life Was Resuming Again, and c) The New Normal. Recommendations for future research include expanding the setting beyond one hospital and investigating the novel study subtheme of attention-distraction. 
Copyright (C) 2019 Brenda Miller All rights reserved 


\section{Dedication}

To all my family and friends, on earth and in heaven, I have accomplished my terminal degree in nursing. Your love and support have been immeasurable. You all were just a phone call, text, email, and a spirit away for my heart. You kept inspiring me and you believed in me. Thank you all so much. I give my love to all. Last but not least, to my maker, Jesus Christ. I kept the faith during many trials and tribulations. I give all the

glory to you. Praise be to God. To my baby sister, Edythe Bernice Willhite November 9, 1964 to April 7, 2019 may she rest in peace 


\section{Acknowledgements}

This journey would not have been possible without the support of so many wonderful people.

First, to my mother and father who believed in me and supported my choice to be a nurse, rest in peace. To my son, Said Abdul-Haqq Nelson you gave me joy and support, I love you son.

To Dr. Ann Mayo, Chairperson, we spent countless hours together either inperson, on the phone, emailing, and zooming. I want to acknowledge how grateful I am to have you as my chairperson. You stimulated me intellectually, provided emotional support, and most of all you believed in me. You were there for me when I doubted myself. Your kinds soft-spoken words of encouragement helped me through the loss of my mother and my best friend, my computer crash, Microsoft word distorting the written words during my analysis, and through the many tears I shed. You never lost hope in me. Thank you from the bottom of my heart.

To my other two extraordinary committee members, Drs. Jane Georges and Caroline Etland, I accomplished my dream! I am so grateful for your feedback and support throughout the nursing program and during the research process. Dr. Georges, I will always remember my first class, Philosophy. Your last PowerPoint of the semester had a profound and lasting impression on me. I did not understand my journey was just beginning. You believed in us when we did not believe in ourselves. Dr. Etland, your countless hours you gave me during the IRB process cannot be taken lightly. Thank you for connecting me to the two nursing units to obtain my participants. To Dr. Mary Jo 
Clark, thank you for refocusing me when I had drifted for too long. Your words were timely.

To all the wonderful staff on each nursing unit and to The School of Nursing, from the bottom of my heart, thank you. I am most appreciative of the research scholarship from Sigma Theta Tau Zeta Mu at-Large. 
Table of Contents

Chapter 1: Introduction ....................................................................................... 1

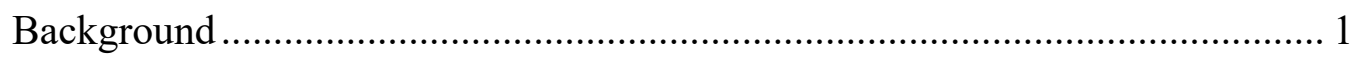

Problem Statement and Study Aims .......................................................... 5

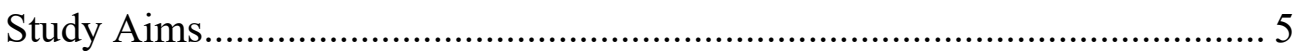

Philosophical Underpinnings and Methodology ......................................... 6

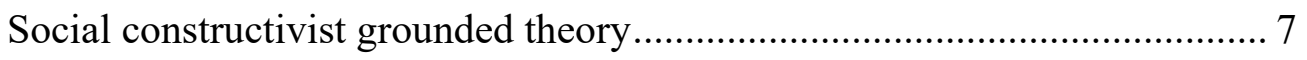

Social constructivism as a philosophy ............................................. 8

Social constructivism as a research method........................................... 9

Social constructivism and the investigator ....................................... 10

Overview of Study Methods ................................................................. 11

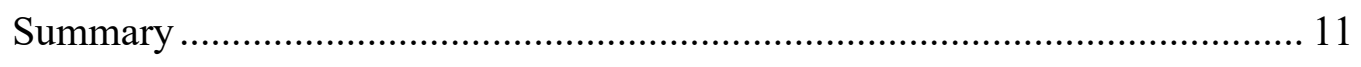

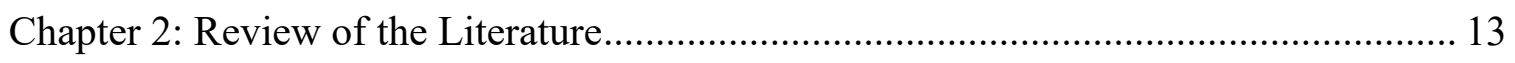

Current Population and Forecasting Through 2050 .................................... 13

Chronic Illness ............................................................................... 14

Hospitalization and Hospital Readmission ............................................... 16

Contributors to Hospital Readmissions ................................................. 18

Strategies to Reduce 30-day Readmission Rates ..................................... 20

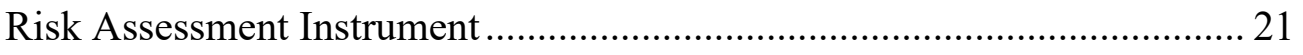

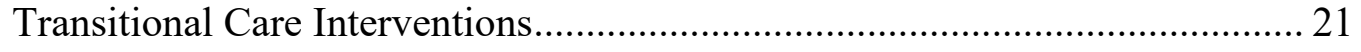

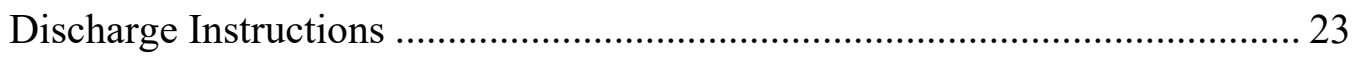


Summary

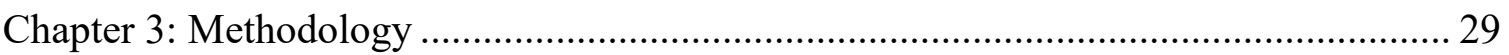

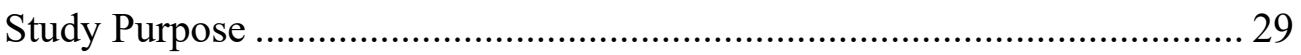

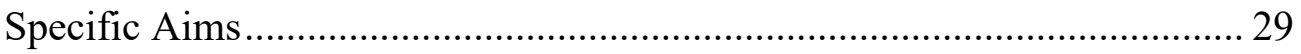

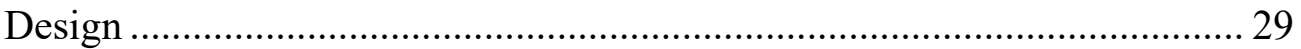

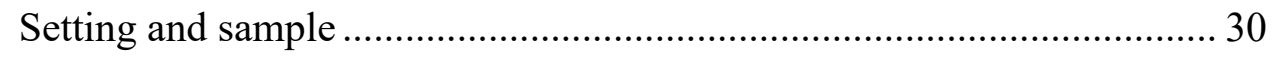

Participant inclusion criteria ............................................................... 30

Participant exclusion criteria................................................................... 31

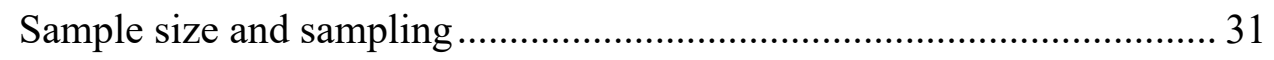

Participant recruitment ......................................................................... 33

Data collection procedures................................................................... 34

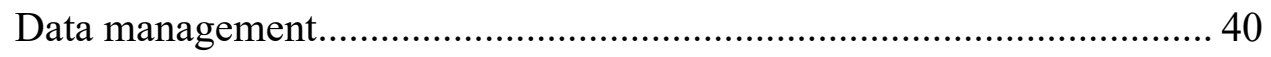

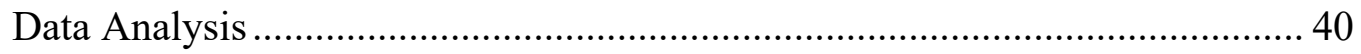

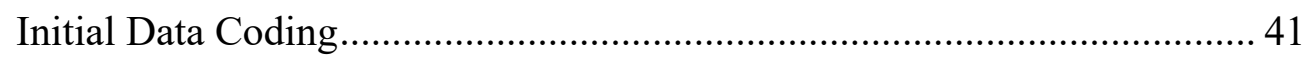

Concurrent Data Generation and Analysis ................................................ 42

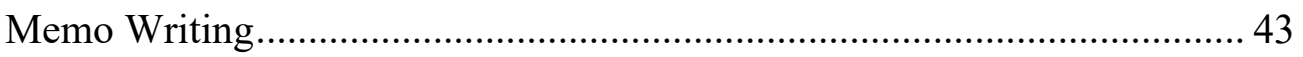

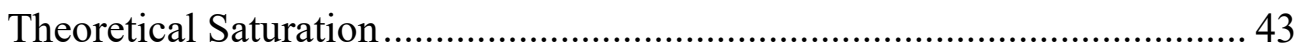

Theoretical Codes and Categories ……….................................................. 43

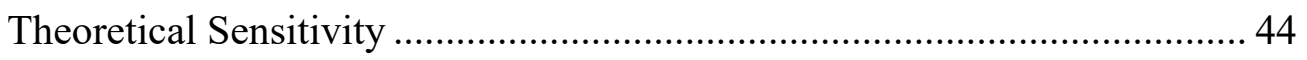

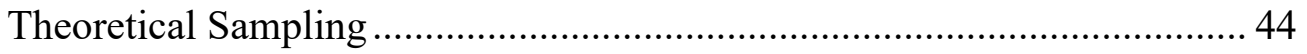

Theoretical Sorting, Diagramming, and Integrating .................................... 45

Protection of Human Subjects .................................................................. 45 


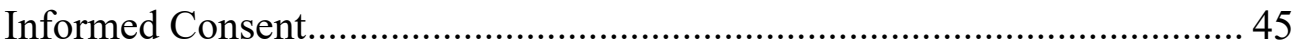

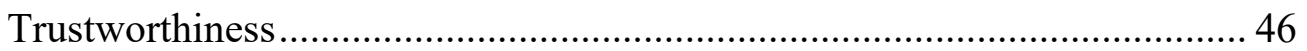

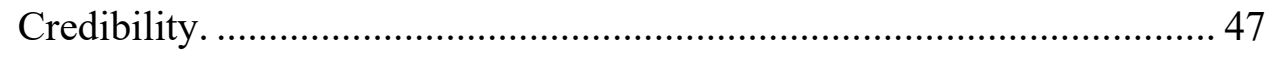

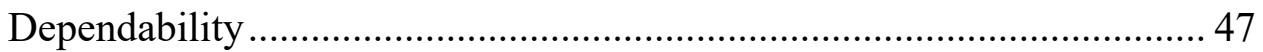

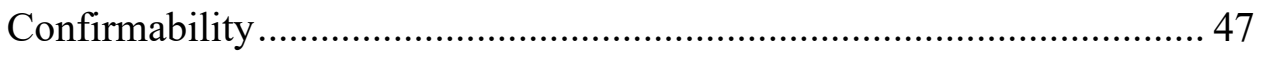

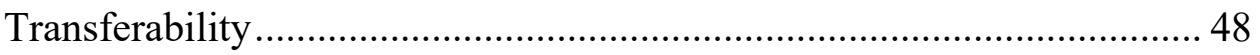

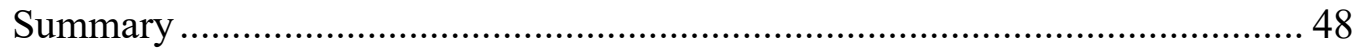

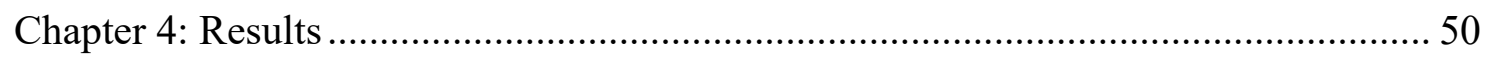

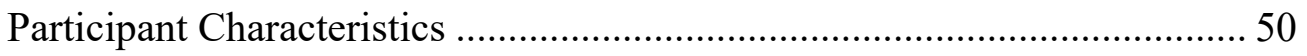

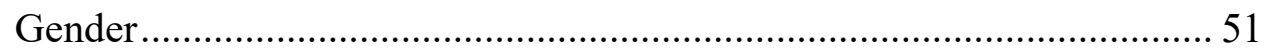

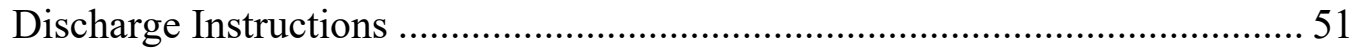

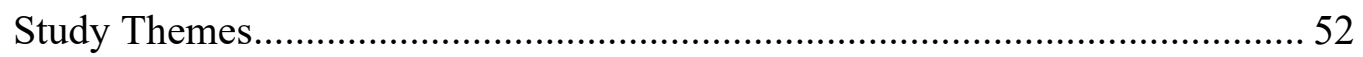

Transitioning Hospital to Home Process …………………........................ 52

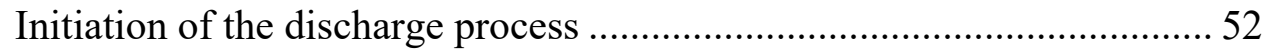

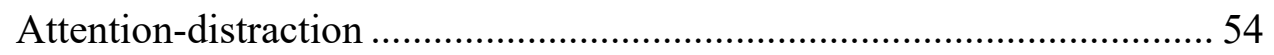

Knowing Their Life Was Resuming Again ................................................ 56

Rejoicing in knowing life was resuming ................................................. 57

Resuming cooking and shopping .......................................................... 58

Worrying about keeping the house clean ................................................. 58

Resuming socializing ........................................................................ 59

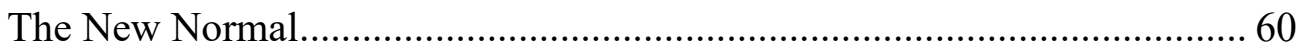


Modifying to return back to life....................................................... 61

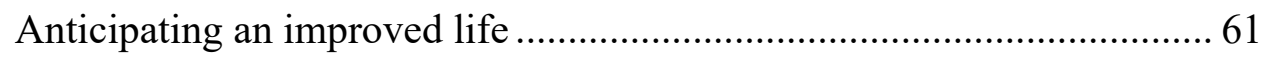

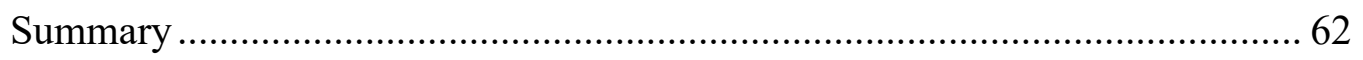

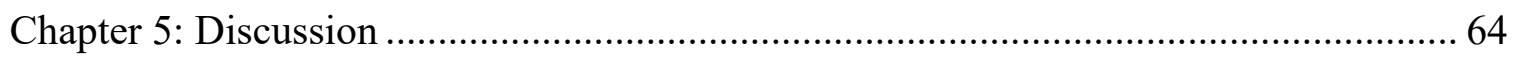

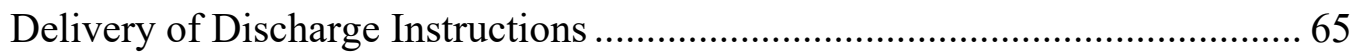

A Novel Sub-Theme: Attention-distraction.......................................... 66

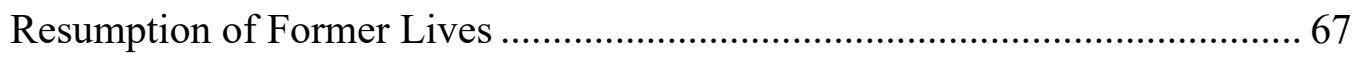

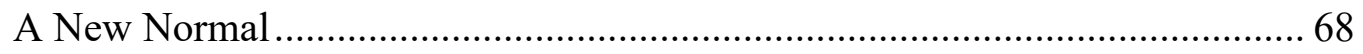

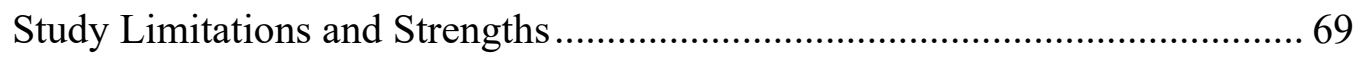

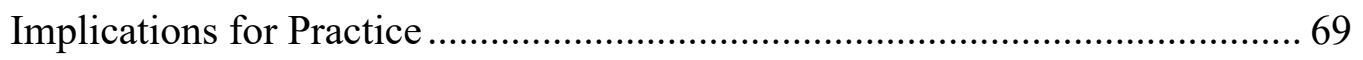

Implications for Research ................................................................... 71

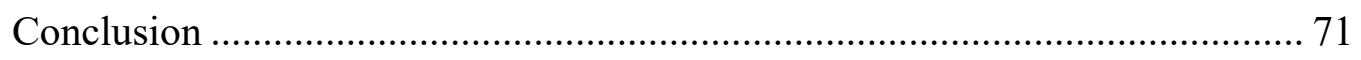

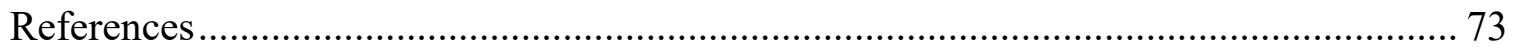




\section{List of Tables}

Table 1: Patient Participant (P) Characteristics ….................................................... 51

\section{List of Figures}

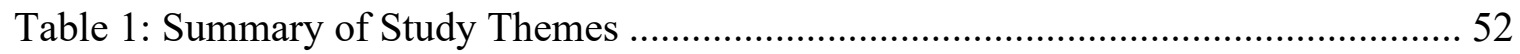

\section{List of Appendices}

Appendix A: Interviewing Questions Reframed................................................... 87

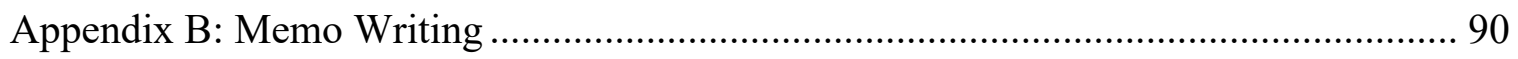

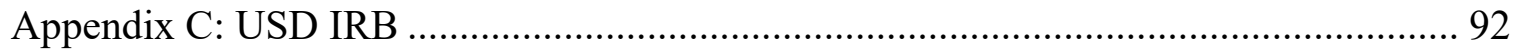




\section{Chapter 1}

\section{Introduction}

In 2012, the world's population reached seven billion people, 562 million ( $8.0 \%)$ of whom were 65 years of age and older. By 2015, the number rose additionally by 55 million (8.5\%). By 2025, the number is anticipated to rise additionally by 236 million people. By 2025 to 2050, the number of people 65 years and older are projected to double world-wide (He, Goodkind, \& Kowal, 2016). This marked increase in this age group will have profound effects on healthcare systems throughout the world.

In the United States, the growth in the older adult population is unprecedented. In 1900, there were 3.1 million people age 65 years and over. By 2010, this figure increased to 40 million. In 2014, the number of people in this age group rose to 46.3 million and is projected to reach 98 million by 2060 (Office of Disease Prevention and Health Promotion [ODPHP], 2017). The percentage of people 65 years and older in the U.S. population increased from $8 \%$ in 2000 to $15 \%$ in 2010 (U. S. Census Bureau, 2016; Werner, 2011). This increase in longevity will bring challenges to the healthcare system, such as people living longer with chronic diseases and the consequent financial impact of caring for them.

\section{Background}

Medicare was introduced in 1966 to treat acute diseases and episodic illness of the elderly and disabled. The number of older adults with chronic diseases in the United States grew. Initially, there were 21 chronic conditions categories identified from 19992010. Since chronic conditions were initially identified, there has been an increase from 21 to 66 identified conditions categories. Of the 66 conditions categories, 27 are 
identified as common chronic conditions and 39 are identified as chronic or potentially disabling conditions (Centers for Medicare and Medicaid Services [CMS], 2019a; U. S. Census Bureau, 2014). In 2003, President George W. Bush signed the Medicare Prescription Drug, Improvement, and Modernization Act to authorize the payment of prescription drug benefits for the population (Oliver, Lee, Lipton, 2004). Chronic illness is slow and progressive and requires ongoing treatment. Chronic illness affects functional status, productivity, and a person's quality of life (Oxford Academy, 2015). In 2012, 63\% of people 65 to 74 years of age managed two or more chronic conditions, with the percentage increasing with age until $83 \%$ of people age 85 years and over were living with multiple chronic conditions (Center for Disease Control and Prevention [CDC], 2015; ODPHP, 2017.

Currently, adults aged 65 years and older represent $40 \%$ of hospitalized patients in the United States, with this percentage projected to rise over the next 40 years as the proportion of older adults in the population increases (CDC, 2015). In 2011, patients living with chronic illness account for $75 \%$ of the $\$ 2$ trillion in annual U. S. healthcare spending (Oxford Academy, 2015). The readmission rate to the healthcare system cost $\$ 12$ to $\$ 20$ billion annually. An estimated one in five of the nine million patients 65 years of age and older hospitalized each year are readmitted within 30 days, further adding to the economic burden of chronic illness in the elderly (Alper, O’Malley, \& Greenwald, 2019; Gorina, Pratt, Kramarow, \& Elgaddal, 2015; Robert Wood Johnson Foundation [RWJF], 2013). For example, Medicare patients 65 years of age and older with a diagnosis of heart failure account for approximately 800,000 hospitalizations per year, with one in four patients returning to the hospital within 30 days (Keenan et al., 2008). 
Frequent readmissions result, in large part, from the difficulty older people encounter in managing their chronic illnesses (CMS, n.d.b; U. S. Census Bureau, 2014). Personal issues affect older adults such as the inability to effectively provide personal care, which includes medication management, health professionals' failure to assess the home environment during discharge planning, lack of supportive care in the home, and health professionals neglecting to determine if an older adult requires a higher level of professional care such as skilled facility or rehabilitation before being sent to their private home (Coleman et al., 2013; RWJF, 2013;).

Medicare and Medicaid expenditures in the United States in 2013 amounted to \$2.9 trillion (CMS, 2015a). High 30-day readmission rates are costly to hospitals and to society. For example, between January and November 2013, the national cost of avoidable hospital readmissions was $\$ 43.1$ billion (Shinkman, 2014). Currently, hospitals are penalized for potentially avoidable readmissions within 30 days of hospital discharge. Since October 1, 2012 the Hospital Readmission Reduction Program (HRRP) has reduced payment to acute care hospitals with excessive readmissions (CMS, 2019b).

Health systems were challenged to reduce 30 -day readmission rates. Strategies to decrease readmission rates include a variety of methods to assist older adults living with chronic conditions and comorbidities. These methods included improved communication with patients, increased family involvement, reconciliation of medications, coordination with community services, use of home health care agencies, telephonic monitoring, telemonitoring, and short-term post-hospital care stays (RWJF, 2013). Transitional care, an extended service provided to patients after a discharge to improve continuity of care and connect them with community support, is another strategy designed to prevent avoidable 
readmissions. By far the most common strategy has been the use of discharge instructions to promote effective self-care at home following discharge from an acute care setting. The challenge to hospitals is to provide effective discharge instructions to prevent readmissions, especially among older adults with chronic illnesses.

Discharge instructions provide education and communicate to patients and caregivers the care needed after a discharge to a private home. Meaningful discharge instructions benefit this age group living with chronic disease and comorbidities, enabling them to successfully provide self-care and reducing readmission rates. Clear and effective discharge instructions that educate older adults on self-care needs are required. In this age of rapid turnover and short-stay hospitalizations, written or verbal discharge instructions may not convey important information needed for a successful recovery at home, including an understanding of medications changes and follow-up appointments with the primary healthcare provider (Coleman et al., 2013; Naylor, Kurtzman, \& Pauly, 2009a; Naylor, Kurtzman, \& Pauly, 2009b).

Patients and caregivers receive discharge instructions after a hospital stay, emergency room visit, or after a procedure (Cienki, Guerrera, Rose-Steed, Kubo, \& Baumann, 2013). These instructions constitute formal communications between healthcare professionals, patients, and caregivers and provide information on self-care needs, medication management, follow-up visits to providers, and any post procedural care. For patients and caregivers, discharge from the hospital is a stressful time. Healthcare professionals may be unable to assess the effectiveness of discharge instructions and to provide alternative teaching interventions due to time constraints and the need to admit the next patient (Alberti \& Nannini, 2013). Therefore, it is often 
unknown how well older patients and their informal caregivers understand the discharge instructions received and the extent to which the instructions are carried out in the home.

\section{Problem Statement and Study Aims}

Older adult patients and their caregivers are routinely provided discharge instructions; however, there is a lack of knowledge regarding the extent to which discharge instructions are actually implemented and the factors that facilitate or impede implementation once older adults are discharged home. This study was designed to determine how older adults recently discharged from an acute care setting and their informal caregivers implemented discharge instructions and identified facilitators and barriers to implementation.

Older adults' and their caregivers' understanding, and implementation of discharge instructions can be a factor in a successful return to home or a contributing factor to readmission. Knowledge of factors that influence implementation of discharge instructions may allow hospitals to develop more effective discharge instructions, improving patient/caregiver compliance with discharge instructions at home. Improved compliance may, in turn, lead to better health outcomes for patients, decreased 30-day admission rates and loss of revenue for hospitals, and decreased societal healthcare costs.

\section{Study Aims}

The specific aims of this study were to:

1. Describe how discharge instructions were implemented in the home setting by adults 65 years of age and older and their caregivers following an acute care hospital discharge. 
2. Identify perceived facilitators and barriers to implementation of discharge instructions among older patients and their informal caregivers.

\section{Philosophical Underpinnings and Methodology}

Grounded theory was the method chosen to elicit information from patients and caregivers regarding how they implemented discharge instructions. Barney Glaser and Anselm Strauss are considered the originators of grounded theory. Barney Glaser's research training was in quantitative methodology, qualitative mathematics, and theory construction. Anselm Strauss's research training was in symbolic interaction and qualitative research; he was educated in the philosophical pragmatist tradition (Urquhart $\&$ Walter, 2006). Glaser and Strauss's goal for grounded theory research was to construct theories grounded in research data that explained phenomena (Glaser \& Strauss, 1967).

Grounded theory, as conceptualized by Glaser and Strauss in 1967, takes various philosophical and methodical stances. Key components of Glaser and Strauss's approach were sampling methods; they developed sample sizes and categories from ongoing data analysis using a theoretical sampling process. Codes are derived from the data. The analysis is derived from constant comparison of cases that develop into theoretical categories. The theory is developed inductively from the data and continuously reevaluated. Glaser and Strauss's final product is a theory explaining the phenomenon of interest that considers all the data and conditions collected.

By the 1990s, Glaser and Strauss's approach had separated into two schools of thought. Out of their differences grew alternative ontological and epistemological lenses that led to other views such as constructivist grounded theory (CGT). The Glaserian approach to grounded theory is that the process is inductive. Data are analyzed to derive a 
product and a formal theory results from the analysis. Glaser had conceived " 18 theoretical family codes" that could be used to derive a theory (Newman, 2007, p. 106). Glaser did not believe in a theoretical framework for grounded theory construction. Strauss and Corbin, on the other hand, used Symbolic Interactionism as a theoretical framework and emphasized symbolic interactionism's importance to a grounded theory because people react toward things based on their perceived importance in their lives. Social interaction among others is the interpretive process used to understand human interactions (Bryant \& Charmaz, 2007; Higginbottom, 2013).

\section{Social constructivist grounded theory}

In the mid-1990s, Kathy Charmaz modified Glaser and Strauss's grounded theory method to develop social constructivist grounded theory (CGT) by offering "a logically consistent set of data collection and analysis procedures aimed to develop a theory" (Charmaz, 2001, p. 245). Charmaz's approach was based on inductive reasoning enabling the development of a theory based on an iterative and systematic process that involved manually coding, categorizing, and comparing data (Higginbottom, 2013). Social CGT, as developed by Charmaz, was used in this study. While based upon the earlier tenets of grounded theory, social constructivist theory was better aligned with the nursing philosophy of patient-centeredness and the importance of social context. Social constructivist grounded theory offers nursing investigators a valid methodology to pursue research questions. Charmaz's social constructivist theory gives voice to the patients, caregivers, and the investigator (Higginbottom, 2013). Social constructivists develop theories from the data, and the investigator constructs a theory based on the grounded data (Charmaz, 2014) 


\section{Social constructivism as a philosophy}

Social constructivism is a philosophical worldview that has been described as interpretivism by Denzin and Lincoln (2011). Interpretivism sees the world from multiple realities; that is, from the investigator's and participants' perspectives. Individuals seek to reconstruct understanding of the social world through perceived knowledge and to understand specific contexts (Creswell, 2013; Denzin \& Lincoln, 2011). Constructivist grounded theory acknowledges that people do not live in a vacuum and construct their own perceived reality (Charmaz, 2014).

This concept of a personalized reality is reflected in the work of German sociologist and philosopher Max Weber (1864-1920). Weber was one of the first to disagree with positivists' beliefs that both natural and social science measured things and people in the same way. Weber believed generalization between the two was impossible because human actions (social science) are not subject to the regularities that govern the world of nature (natural science). He further believed that people, in contrast to things, could be understood by their behaviors and underlying motivations. He did not take a strict interpretivist stance; rather, he believed investigators did not have the same culture and beliefs as those they observed. His approach emphasized the meaning of actions in the social sciences must be understood within the context of peoples' lives. He attempted to merge interpretivist and positivist approaches to gain a full understanding of natural and social sciences separately (Ormston, Spencer, Barnard, \& Snape, 2013). Positivists took a more scientific approach, with the investigator more of a non-active participant in the research. Weber noted the positivist approach analyzed material by observing and recording evidence. Social constructivism emphasizes that knowledge is actively 
constructed by human beings in the world in which people live and from a complex view instead of a narrow or passive perspective (Creswell, 2013; Ormston et al., 2013). Constructivist grounded theorists use data obtained from interacting with individuals to determine how participants view their situation and why they view it that way. Patients and caregivers in this study reconstructed their understanding of the hospital discharge experience through their own lenses and shared that experience with the investigator.

\section{Social constructivism as a research method}

Charmaz, as well as several other theorists, continued following the constructivist intent into the mid-1990s, giving a "voice" to research participants. Charmaz (2006) defined the grounded theory method as "systematic, yet flexible guidelines for collecting and analyzing qualitative data to construct theories 'grounded' in the data themselves" (p.

2). Charmaz linked social constructivism to grounded theory and articulated the method for nursing research (Higginbottom, 2013).

Unlike Glaser, Charmaz (2006) expressed the past and present experience of people with research practices that helped to construct a theory grounded in the data collected. According to Charmaz, investigators cannot separate themselves and their experiences from the phenomenon under study and be objective about the data. Instead, the investigator brings his or her subjective interpretation to the analysis of the data. Symbiotically, the interpretations of the investigator, patient, and caregiver form multiple realities, each having socially constructed realities that influence the research. (Charmaz, 2006; Wetz et al., 2011). This directs the research toward the development of a theory. 


\section{Social constructivism and the investigator}

Social constructivist theory rejected the Glaser and Strauss philosophy that data and theories are "discovered." Charmaz moved from the stringent, positivist approach and systematic and complex coding process to adopt an inductive, comparative, emergent theory and an open-ended approach to grounded theory. The investigator must acknowledge and assess his or her past experience and what is brought to the analysis aspect of a study (Charmaz, 2014).

One reason for selecting the current topic and Charmaz's approach was the investigator's prior knowledge of older adults and caregivers emanating from years of experience as a home health and hospice nurse. The investigator's background involves 40 years of nursing experience including over 20 years of community nursing. The investigator spent over 15 years as a nurse case manager, more than 17 years as a full- or part-time admissions nurse, and over 10 years as a medical-surgical nurse and house supervisor.

The investigator worked in home care making home visits, completing admissions and evaluations after a discharge. Since the investigator has a rich experience as a home health nurse, the risk of bias in interpreting what and how participants viewed their discharge instructions was considered constantly as the data were interpreted. With the investigator having past experience in home care, she avoided discussing personal experiences or past patient experiences, so the focus remained on the process experienced by the patients and caregivers. The investigator did not interject her thoughts. 


\section{Overview of Study Methods}

This study used an emergent qualitative paradigm, specifically, social constructivist grounded theory. Emergent methods are appropriate for a study where a gap exists in knowledge, such as how discharge instructions were implemented by patients 65 years of age and older and their caregivers. Interviews were conducted in the private homes of patients and caregivers within seven days of discharge from an acute care hospital. The investigator asked open-ended questions. In keeping with social constructivist grounded theory, constant comparative data analysis allowed the investigator to evaluate questions asked and to reword questions as needed to increase understanding as the data were collected. This method permitted the investigator to revisit patients and caregivers to enrich the responses. After the interview, coding began with an inductive analytical process that moved toward deductive reasoning. A theory developed from the information collected during the study.

\section{Summary}

The percentage of adults 65 years of age and older in the United States will double by 2050 . This age group uses the healthcare system more than other age groups. Chronic conditions and comorbidity contribute to high readmission rates. Readmission of discharged patients contributes to increased hospital costs since many readmissions are not reimbursed by CMS. Healthcare systems use various strategies to reduce 30-day readmission rates including provision of discharge instructions to promote self-care at home and community participation from healthcare professionals. Successful implementation of discharge instructions in the home may reduce costly readmissions; 
however, it is unknown whether and how discharge instructions are implemented and the barriers and facilitators to implementation.

In this study, Charmaz's social constructivist method was used in interviews with older adults and their caregivers to explore how they implemented discharge instructions in the home and their perceptions of facilitators and barriers to implementation. This method provided an emergent qualitative paradigm and gave voice to the patients, caregivers, and investigator. Chapter two discusses a review of relevant literature. 


\section{Chapter 2}

\section{Review of Literature}

This grounded theory study gathered critical factors that influenced implementation of discharge instructions by older adults and their caregivers after an acute care setting discharge to home. The study aimed to gain an understanding of the social process associated with implementation of discharge instructions.

This review of literature examined the current extent and forecasts of growth in this population, the extent of chronic conditions in the older adult population, the complexity of medication management as it pertains to hospitalization, readmission rates, and finally, the financial impact of readmissions. Then the review examined the current state of the science on 30-day readmission interventions, focusing on the discharge instructions given during a discharge from the hospital.

\section{Current Population and Forecasting Through 2050}

In 1900, the number of people 65 years and older in the United States was 3.1 million. In 2000, there were 35 million people 65 years and older. In 2010, the last census reported, there were 40.3 million people 65 years and older, an increase of 5.3 million from the 2000 census. The 2010 figure represented $13 \%$ of the total population, an increase from $12.4 \%$ in 2000 (U. S. Census Bureau, 2011). In 2014, 20\% of the total U. S. population, or 77 million people, were adults 65 years of age and older (Barr, 2014; U. S. Census Bureau, 2014). According to the U. S. Census Bureau (2014), the 65 years and older adult population is projected to increase to 2.4 million by 2050 and then increase to 98 million by 2060 (Harris \& Wallace, 2012; ODPHP, 2017). These figures 
are noteworthy because of the potential impact on the healthcare system. Healthcare systems will need to prepare to care for the growing number of people 65 years and older

\section{Chronic Illness}

As patients' life expectancy increases, older patients will live with one or more chronic conditions. A call for public action for older adults is to live healthier lives with their chronic illness by keeping physically active, completing health screenings, and receiving immunizations (CDC, 2015; Oxford Academy, 2015; National Center for Health Statistics [NCHS], 2014, 2016; ODPHP, 2017; U. S. Department of Health \& Human Services \& U. S. Department of Justice, [USDHHS \& USDOJ], 2016). In the United States, chronic illness accounts for $70 \%$ of deaths and $75 \%$ of healthcare costs (Harris \& Wallace, 2012). However, with advanced technology and effective care, chronic disease progression can be slowed, and older adults will live longer with multiple chronic conditions (NCHS, 2014, 2016). Providing effective discharge instructions to promote adequate self-care in the home is imperative as the lengths of stay in the hospitals are shorter and older adults are returning home sooner to self-manage chronic diseases and comorbidities.

The U.S. Department of Health and Human Services (2010) has defined chronic illnesses as "conditions that last a year or more and require ongoing medical attention and/or limit activities of daily living" (p. 1) that are frequently undiagnosed until late in the disease trajectory. Two or more concurrent chronic illnesses are termed comorbidities. Approximately one in four Americans will acquire comorbidities, such as diabetes, as they age. The incidence of diabetes increases with age. Between 2025 and 2050 , the projection of diabetes in older adults 65 years and older will increase by 4.5 
times, compared to the rest of the population, which will only increase three times. The prevalence of diabetes in older adults aged 65 years and older varies from $22-33 \%$ using A1C as diagnostic criteria (Kirkman, et al., 2019). The treatment of an older adult with diabetes may complicate management of comorbid diseases, such as cardiovascular and microvascular diseases, that will increase the healthcare cost for an aging person. The consequences of chronic illness were reported in Logan, Guo, Dodd, Muller and Riley's (2013) study on chronic illness in 36 rural census tracts in North Florida. In this study, the sample population of 2,381 people included adults aged 25 and older. During telephone interviews, professional interviewers asked for only the oldest male to maximize the age of the sample. The mean age was 56.2 years $(S D=15.1$, range $25-94$ years). Comparing income to rural versus urban regions in the United States, the population income was lower in the rural regions. Across the United States, four chronic conditions, : diabetes, cardiovascular disease, cancer, and arthritis, are most commonly found in lower income rural regions. These four common conditions are possibly preventable and are costly to treat; for three of these conditions, the U. S. spent (a) $\$ 245$ billion for diabetes in 2012; (b) \$442 billion for cardiovascular disease in 2011; and (c) \$128 billion for arthritis (Erdem, Prada, \& Haffe, 2013).

The cost of chronic illness care among the elderly is even higher due to multiple comorbidities. People living with chronic illnesses and comorbidities must cope with disease interactions and additional problems, such as managing multiple medications, that can affect their quality of life. Addressing chronic conditions and comorbidities in both rural and urban communities will be essential to improve people's quality of life and decrease the financial burden of chronic illness on the healthcare system. 


\section{Hospitalization and Hospital Readmission}

Comorbidities contribute to poor health, complicate management of chronic disease, and frequently contribute to unnecessary hospitalizations (CMS, n.d.a; USDHHS, 2010). Chronic illnesses are incurable conditions that encompass the whole person and often contribute to longer length of hospital stays and more frequent readmission (Harris \& Wallace, 2012)

Hospitals were tasked by CMS when the HRRP program was implemented to decrease readmission rates. Hospitals needed to reduce the readmission rate by improving discharge planning, providing better education for patients and caregivers, improving community services connections, and initiating discharge needs for patients within 24 hours after an admission.

Readmission rates, especially for older adults with comorbidities, are costly to the healthcare system (Healthcare Cost and Utilization Project [HCUP], 2009). The goal is to prevent readmission. From 2004 to 2009, there was very little change in readmission rates followed by a spike in rates after implementation of the Patient Protection and Affordable Care Act (2010) was enacted. For example, more than seven of every 100 adults admitted for congestive heart failure in 2011 were readmitted within 30 days, resulting in a cost to Medicare of $\$ 1,747,000$. Similarly, more than two of every 100 adults admitted for cardiovascular disease in 2011 were readmitted within 30 days at a cost of $\$ 568$ million (Hines, Barrett, Jiang, \& Steiner, 2014). These 30-day readmission rates and high costs have been attributed to inadequate self-care following discharge (CMS, 2015a; Coleman et al., 2013). 
In 2014, Congress passed the Improving Medicare Post-Acute Care

Transformation Act of 2014 (IMPACT Act) that required standardized patient assessment data including improved planning for discharge to inpatient rehabilitation and skilled nursing settings, home health agencies, and long-term care hospitals. This measure was designed to motivate clinical professionals to improve their assessment of older adults following discharge and to reduce readmission rates (CMS, 2015b). This measure improves facilities' or agencies' assessments but will not benefit older adults who have minimal to no services after a discharge or who are discharged to home.

In 2005, the government enacted the Deficit Reduction Act (DRA) to allow states to modify state Medicaid programs by allowing premiums and cost-sharing by certain Medicaid recipients. Part of this act was designed to foster greater responsibility for their own care among both healthy Medicaid enrollees and those with chronic illnesses. There was a high deductible health plan associated with the program. Subsequently, Congress enacted the Patient Protection and Affordable Care Act (ACA) in 2010 that led to the Hospital-Acquired Condition (HAC) Reduction program in 2012. HAC was established to improve patient safety and reduce the number of hospital-acquired conditions such as pressure sores and hip fractures after surgery. The approach saved Medicare approximately $\$ 350$ million every year by reducing payments to hospitals based on poor performance in managing hospital-acquired conditions. This led the government to establish the HRRP, which provides financial incentives to hospitals to reduce costly and unnecessary readmissions (CMS, 2015a).

Despite the HAC Reduction Program, healthcare costs continued to rise and readmission rates did not decline. With the initiation of the HRRP, CMS changed its 
focus from readmission within 24 hours to readmission for the same diagnosis within 30 days of discharge. The three initial diagnoses for which hospitals did not receive reimbursement for potentially preventable readmissions within 30 days were pneumonia, acute myocardial infarction (AMI), and heart failure (HF). Additional diagnoses have been added to this list, such as chronic obstructive pulmonary disease (COPD), total knee arthroplasty (THA/TKA), central line-associated bloodstream infection (CLABSI), and catheter-associated urinary tract infection (CAUTI) (CMS, 2015a; CMS 2015b).

Hospitals across the United States were impacted financially by reductions in reimbursement from CMS for preventable readmissions for these diagnoses. In 2013, slightly more than 2,000 hospitals nationwide incurred a cumulative total of more than $\$ 300$ million in penalties. Some of the hospitals incurred penalties of thousands of dollars but those that remained in violation and did not improve their readmission rates incurred millions of dollars in penalties (CMS, 2015a; Zhang et al., 2014).

\section{Contributors to Hospital Readmissions}

Among the top five health-related issues that contribute to a readmission and hospital penalties are heart failure (HF), pneumonia, COPD, psychoses, and gastrointestinal problems. Heart failure was one of the three initial diagnoses the HRRP identified to give hospitals incentives to reduce the readmission. Besides the diagnosis of HF, several other factors were found to contribute to readmission at the clinician or system level such as (a) premature discharge, (b) inadequate post-discharge support, (c) failed handoffs between clinicians, (d) hospital-acquired infections, pressure ulcers, and patient falls, and (e) therapeutic errors while hospitalized. In the U. S., $33-69 \%$ of 
medication nonadherence increases the rate of readmission (American Hospital Association [AHA] 2015; CMS, 2015a; Jencks, Williams, \& Coleman, 2009).

Hospitalization of adults 65 years and older living with chronic illnesses often leads to new, changed, or discontinued medications. Taking two or more prescription (or nonprescription) medications increases the risk for drug interactions, discrepancies, and adverse consequences. A cross-sectional study by Bao, Shao, Bishop, Schackman, and Bruce (2012) evaluated the prevalence of potentially inappropriate medication among people 65 years of age and older who received home health or hospice services. Interviews were done in-person with designated home health staff members $(n=3,124)$. Data were also collected by review of patients' medical records. On average, the participants were taking 11-15 medications. Thirty-eight percent of the older adults were taking at least one inappropriate medication and $26 \%$ had at least one inappropriate medication with a high potential for a serious adverse reaction. Prescribing of more than one medication was a predictor for potentially inappropriate medication use and increased the risk for adverse reactions. Another retrospective study by Cornu and colleagues (2012) found similar results. Among 189 discharged patients, the researchers found 172 discrepancies between the medication list sent to the physician and the list that was sent home with the patients at discharge. Almost $50 \%$ of the patients had at least one discrepancy.

Use of the wrong medication, dose inaccuracies, or incorrect frequency or route of administration can also lead to a hospital readmission before a patient is admitted to home health. Medications, including any changes from prior regimens, should be reviewed with both patients and their caregivers prior to hospital discharge to decrease 
risk for a readmission and lower the readmission rate of $33-69 \%$ due to medication errors.

\section{Strategies to Reduce 30-day Readmission Rates}

With the rapidly growing older adult population, hospital readmissions are placing a financial strain on both the healthcare system and Medicare (Coleman et al., 2013). CMS has mandated healthcare systems reduce the 30 -day readmission rate but has made no recommendations as to how these reductions will be accomplished. (CMS, 2015a). To lower the rate of readmission, hospitals are focusing on the following:

- Better coordination of care among providers, and patients and their caregivers through improved communication;

- Implementation of electronic medical records to share information internally and with external providers to improve continuity of care;

- Programs designed to facilitate the transition from hospital to home, including (a) palliative care, a holistic care approach for continuity of care, and (b) transitional care, an extended in-home care service (AHA, 2015; CMS, 2017; Enguidanos et al., 2015; Naylor et al., 2009b).

Another significant factor that can affect hospital readmissions rates is poor discharge planning. Specifically, this includes (a) poor care coordination, (b) lack of planning specific to the home environment, (c) failure to consider planned transitions, (d) failure to determine the need for a higher level of care before a discharge occurs from the hospital; and (e) the absence of supportive care in the home. These factors contribute to a higher risk for a 30-day readmission (Coleman et al., 2013; RWJF, 2013). Strategies that 
have been used to reduce readmission rates have included risk assessment software, transitional care, and discharge instructions.

\section{Risk Assessment Instrument}

In a quasi-experimental study, Bowles et al. (2015), introduced a Decision Support System (D2S2) software to analyze data on three identified hospitals computers. A risk assessment instrument was used to collect data to examine the effect on 30- and 60-day readmission. On an admission, information was collected on patients considered either high- or low-risk for a readmission. During the admission, the risk assessment instrument tool assisted case managers or discharge planners to identify patients in need of post-acute care, to assess the appropriate intermediate level of care, to improve the discharge process, and to increase education for patients or their caregiver before discharge. For patients identified as high-risk for 30-day readmissions, the readmission rate decreased in the experimental phase from $22.2 \%$ to $9.4 \%$ and the low-risk patient rate decreased from 13.1 to $8.8 \%$. Similar reductions were seen in the 60 -day readmission rates (Bowles et al., 2015).

\section{Transitional Care Interventions}

Healthcare systems implemented transitional care for patients after a hospital discharge to improve continuity of care, connect with community support, and prevent readmission. Transitional care is teams-based care that involves interdisciplinary healthcare professionals to improve patients' outcome and care and reduce healthcare cost. Transitional care interventions range from telephone calls from a clinician, a pharmacist, or a patient's primary care clinic to other interventions such as home visits, telemonitoring, medication management, and identifying high-risk patients with chronic 
conditions such as heart failure (HF) (Dudas, Bookwalter, Kerr, \& Pantilat, 2001; Phatak et al., 2016).

While there is an increased implementation of transitional care, it is not a new concept. Brooten et al. (1995) conducted a randomized study focusing on the use of Advanced Practice Nurses (APNs) for home care as compared to care provided by family or friends. The study demonstrated effectiveness of the approach in terms of improved patient outcomes and reduced cost. However, use of ANPs in the home is costly.

Additional studies have employed APNs, primarily clinical nurse specialists CNS), to make telephone contact, arrange appointments with a patient's primary care provider, and provide education and counseling (Brooten et al., 1986; Kwok, Lee, Woo, Lee, \& Griffith, 2008; Naylor et al., 1999; Naylor et al., 2004; Naylor et al., 2009a). These strategies demonstrated reduced readmissions, lengthened time between hospitalizations, and a financial benefit to hospital systems.

Despite the findings regarding the efficacy of transitional care, there are some disadvantages to this strategy. Under Medicare reimbursement requirements, when an agency sends nurses into the home, that agency must operate under strict regulations that limit nurses' visits. Medicare regulations have stringent guidelines called "Conditions of Participation." The conditions of participation closely monitor nursing visits to assure nurses are making visits to the home that are considered "skilled" visits and are not deemed custodial. These guidelines can markedly restrict nurses' visits (CMS, 2017).

The Balanced Budget Act of 1997 allowed APNs to function as primary healthcare providers in areas and states where there is a shortage of physicians and to receive payment for their services (American Nurses Association, n.d.). Home health 
nursing remains under the conditions of participation for Medicare and Medicaid services for payment for their services; however there are limitations on the number of visits these nurses can make to the home. Such limitations may not permit home health nurses to meet the needs of many older patients, forcing them to rely on self-care or care by family and friends.

\section{Discharge Instructions}

The most commonly used strategy for reducing 30-day readmission rates is the provision of discharge instructions that enable patients and/or their caregivers to engage in effective self-care and management of their health needs. Hospitals have determined decreasing readmission rates might result from improving the process of discharge planning by initiating discharge planning for patients within 24 hours of an admission. Hospitals strive to ensure patients have a safe discharge from hospital to home by providing ongoing education during the hospital stay.

Discharge planning requires an interdisciplinary approach that includes healthcare professionals, patients, and caregivers. In recent years, more hospitals are mandating that caregivers/supportive person(s) must also be involved in the development of the plan and be part of the discharge process, all of which eventually affects the discharge instructions.

Discharge instructions are designed to be a communication process between a healthcare professional and the patient prior to leaving the hospital. The purpose of discharge instructions is to enable patients (and caregivers) to understand the treatment plan, the illness(es), and medication self-administration, to assume or resume self-care responsibility, and, ultimately, to resume or modify their pre-hospital lifestyles (RWJF, 2013). 
Discharge instructions are typically provided prior to leaving an acute care hospital. One or multiple healthcare professionals can deliver discharge instructions. Discharge instructions are meant to be a comprehensive plan for self-care delivered through individualized educational interventions designed to prepare patients for recovery at home. Topics typically included in discharge instructions are self-care management, activity progression, diet modifications, medication management, and follow-up care with the primary care provider (PCP) and/or specialists (Coleman et at., 2013).

Several studies have examined the use of discharge instructions. One qualitative thematic analysis study by Cobley, Fisher, Chouliara, Kerr, \& Walker (2013) compared two groups of patients: those discharged following a stroke with an early support discharge team and those receiving conventional services. The early supportive discharge group consisted of 19 patients and 9 caregivers. Patients' mean age was $69.8 \pm 13.4$ years, while the mean age of caregivers was $72.8 \pm 14.1$ years. The conventional services group comprised eight patients and seven caregivers. Interviews were conducted with a "high degree of control over the conversation" (Cobley et al., p. 752) in the patient's residence within one to six months after a hospital discharge. Common themes in both groups of interviews were (a) limited support for dealing with caregiver strain, (b) lack of patient and caregiver preparation for the discharge to home, (c) the abruptness of the discharge, (d) inadequate knowledge and understanding of stroke, its causes, and needed lifestyle changes, (e) lack of an easy to understand information format, and (f) failure to make patients and caregivers feel a part of the decision making and discharge planning processes. Findings confirmed the idea that more support was needed for caregivers and 
that discharge planning and instruction needs to include both the patients and caregivers (Cobley et al., 2013).

An exploratory, qualitative grounded theory study by Enguidanos et al. (2015) obtained feedback from readmitted chronically ill patients $(n=9)$. All were males, with a mean age of $70.1 \pm 9.5$ years, lived alone, and had no identified caregivers. Some of the identified themes contributing to their subsequent readmission included (a) the lack of caregiver support, (b) patients' lack of motivation to provide self-care, (c) poor quality of self-care, (d) lack of desire to follow-up with PCPs, and (e) lack of internal desire to pursue aggressive care or accept their illness. In addition, $42 \%$ of these readmitted patients reported medication errors upon transition to home. Study authors suggested changes to discharge instructions that included (a) preparation for use of medical equipment and (b) scrupulous discharge teaching regarding home medication administration.

A quantitative study conducted by Coleman et al. (2013) explored 237 patients' understanding and execution of discharge instructions to meet self-care needs. A study nurse initiated the first contact in the hospital, and then followed patients to their homes within one week of discharge to administer the Short Test of Functional Health Literacy in Adults (STOFHLA) to assess literacy and the Clock Drawing Test to screen for cognitive ability. Two questions in the STOFHLA pertained to self-efficacy. Low scores indicated inadequate functional health literacy while high scores indicated adequate functional health literacy. Participants were 55 years of age or older living in private homes and scored $41 \%$ or less on the clock drawing assessments, which was an 
indication of possible cognitive deficits, and $21 \%$ or less on the STOFHLA, which indicated inadequate or marginal functional health literacy.

Three significant variables predicted success in understanding and executing the discharge instructions: (a) health literacy as indicated by the STOFHLA score, (b) cognition (measured by scores on the clock drawing test), and (c) self-efficacy in understanding. This study may provide insight to healthcare professionals who label patients or caregivers as noncompliant that discharge instructions need to be customized to meet patients' and caregivers' level of cognition and health literacy.

Investigators have also begun to examine issues in the home that may interfere with implementation of discharge instructions. In a randomized trial by Biese et al. (2014), a total of 120 participant patients 65 years and older living in private homes who had been discharged from an academic emergency room were enrolled in either an intervention or comparison group. The mean age of all participants was 75 years ( $S D$ of \pm 7.6 years). Patients or their caregivers in the intervention group received post-discharge telephone calls 1 and 3 days after the patient's discharge. The intervention telephone calls were designed to improve discharge care by reviewing the discharge instructions, facilitating home services, scheduling follow-up appointments, and assisting with medication management. Additional telephone calls were made at 5 and 8 days and 30 and 35 days to assist with discharge instruction compliance. A placebo group only received a patient satisfaction survey telephone call. A third group, the control group, did not receive any telephone calls. The intervention group showed 1.8 times greater compliance in following up with their physician within five days (54\% of participants versus $37 \%$ of the control group and $20 \%$ of the placebo group). There was no significant 
difference among the groups regarding compliance with their prescribed medications. Additional study is warranted to better understand if these results are replicated across multiple sites or with more diverse patient populations and most importantly, if these types of telephone call interventions can reduce readmissions and increase cost-savings.

\section{Summary}

Returning home after a hospital stay can be exciting and overwhelming for the older adult and his or her caregiver. The bridge to a successful discharge starts with admission to the hospital. Since the passage of the ACA in 2010, many new concepts have arisen to improve the care of patients after a discharge. Hospitals have been challenged to improve the discharge process. Discharge instruction was designed to assist the patient with a smooth transition from acute care to home. Many older adults have multiple health problems that contribute to readmissions. With multiple health problems and chronic conditions, understanding the discharge instructions can potentially be overwhelming. Implementation of discharge instructions at home was studied within this group.

Reducing 30-day readmission rates that result in decreased Medicare spending requires effective interventions for chronically ill patients. Hospitals continue to receive financial penalties that affect the hospital bottom line and potentially lead to financial disaster for hospitals, such as potential closures (CMS, 2015a). A shorter length of stay and earlier discharge of chronically ill patients necessitates alternative methods to support them in the home. For this reason, knowledge of patient and caregivers' perspectives regarding implementation of discharge instructions was needed. 
Discharge instruction was designed to communicate continued care after a discharge to home including aspects such as medication management, continuity of care for recovery, follow-up with healthcare providers, and should include a caregiver when possible. Factors can interfere with the patient's ability to implement the instruction. Preventing readmission will be a continued challenge moving forward.

Chapter 3 addresses the methods used to collect, analyze, and report information on how patients and caregivers implemented discharge instructions in the home setting and their perceptions of facilitators and barriers to implementation. 


\section{Chapter 3}

\section{Methodology}

Chapter 3 addresses the study purpose, specific aims, and research design used. Sample size, recruitment, ethical considerations, data collection, and data analysis processes are also addressed.

\section{Study Purpose}

A qualitative, grounded theory approach was appropriate for this study because this method was a systematic and an interpretive approach to generating a theory from data. This study generated an explanation of a social issue and future implications to design interventions to promote effective discharge instruction, enhance patient recovery, and avoid rehospitalization during the precarious first 30 days following discharge. Specific Aims

The primary aims of this study were to accomplish the following:

1. Describe how discharge instructions were implemented in the home setting by adults 65 years of age and older and their caregivers following an acute care hospital discharge.

2. Identify perceived facilitators and barriers to implementation of discharge instructions among older patients and their informal caregivers.

\section{Design}

This study used an emergent qualitative paradigm, specifically social constructivist grounded theory. The constructivist approach was chosen over other grounded theories because this qualitative research design allowed the investigator's past experiences to be acknowledged. It is acknowledged that the investigator in such a study 
is not an objective observer. From the social constructivist perspective, the investigator aimed to enter the participant's setting and situation to learn from the inside (Charmaz, 2014).

An emergent method is defined as an open-ended method that is inductive and indeterminate, that begins with the empirical world, and that builds inductively as the events unfold and knowledge emerges. Emergent methods are appropriate for an area that has been understudied to check emerging theoretical properties as they develop from focused data (Charmaz, 2006).

Grounded theory is a qualitative research design derived from symbolic interactionism, a branch of interpretivism. Symbolic interactionism uses symbols, words, interpretation, and languages between people and investigator (McCann \& Clark, 2003). The outcome of grounded theory is to generate or discover a theory (Creswell, 2008). Theory development in this study was designed to generate or ground a process in data from participants who had experienced a discharge home from an acute care hospital after receiving discharge instructions.

Setting and sample. A 243-bed licensed hospital in Southern California was used to gain access to potential study participants. Data were collected in private homes in San Diego County. Participant referrals were received from a nursing director in the acute care setting of a Southern California hospital. Discharged patients and their informal caregivers comprised a study dyad.

Participant inclusion criteria. Discharged patient participants were 65 years of age or older and their caregivers were 21 years of age or older. The participants were discharged from an acute care hospital and had an informal caregiver residing in the 
home or visiting at least one time per week. Discharged participants resided within 25 miles of the discharging hospital and had a working telephone. All participants spoke English and demonstrated adequate hearing and vision, as judged by the PI, to complete the study consent forms. Both agreed to separate interviews. The participants that met inclusion criteria were initially evaluated based on age only. Further evaluation of other criteria occurred after the Stroke Rounds (see below). Walking rounds further delineated other inclusion and exclusion criteria.

Participant exclusion criteria. Discharged participants or caregivers who had a mental health disorder left untreated, dementia, or patients with an active cancer diagnosis were not eligible to participate. Similarly, discharged participants or caregivers who were unable to hear or speak or who could not speak English were excluded from the study. Patients discharged to a long-term care facility or with plans to enter hospice or a palliative care program were ineligible. Finally, a patient who did not have informal caregivers willing to participate or who were unwilling to be interviewed separately were not eligible for inclusion.

Sample size and sampling. Data were collected until a rich lived experience was obtained from the participants. The sample size was expected to be 15 to 30 patientcaregiver dyads. The final number of participants was 10 participants and 10 caregivers that resulted in collection of sufficient data to potentially construct a grounded theory (Charmaz, 2012).

Two approaches to sampling were used during this grounded theory study: Purposive sampling initially identified potential participants for the study. Purposive sampling sets criteria for representation of key attributes identified in the inclusion 
criteria at the outset of data collection (Charmaz, 2014). The investigator set out to select research participants who were 65 years of age and older, discharged from a San Diego acute care hospital, who resided in San Diego County.

The initial target sample for the study was patients 65 years of age and older. However, the investigator found that potential participants 80 years of age or older were consistently ineligible to participate based on study exclusion criteria. This led to a purposive change to restrict recruitment to persons 65 to 80 years of age and to exclude those over 80 , resulting in a potential loss of qualified participants.

Once data analysis began, theoretical sampling based on emerging data categories helped to identify additional potential participants to explore emerging categories (Charmaz, 2012). The original definition of theoretical sampling by Glaser and Strauss (1967) has been undisputed. It reads, "The process of data collection for generating theory whereby the analyst jointly collects, codes, and analyzes his data and decides what data to collect next and where to find them, to develop his theory as it emerges" (p. 45).

According to Charmaz (2012), the objective of theoretical sampling is theory construction through examining the empirical world and theoretical ideas. Charmaz highlighted this as an important step and stressed that theoretical sampling is to occur after the initial data collection and analysis, progressively focusing data collection to refine and integrate data that coalesce into a theory. The rationale for this was that grounded theory emerges differently from other qualitative inquiry because the properties of categories may not emerge until the investigator has pursued lines of inquiry that are based upon learning from earlier participants (Charmaz, 2014). The investigator 
conducted theoretical sampling as categories emerged during the ongoing data analysis process.

Participant recruitment. Participants were recruited from a hospital in San Diego. The research director in the hospital arranged for the investigator to meet with other nurse leaders and staff on the selected unit. A Microsoft PowerPoint presentation was presented to the nurse leaders and their staff. After the presentation, the investigator met with the director of research, manager of the unit, stroke CNS coordinator, and clinical lead coordinator. The meetings were held on the unit. Rounding on the unit occurred from November 29, 2016 to April 20, 2017. Initially the age inclusion criteria started the evaluation for participants. Further evaluation of the other criteria occurred after the stroke rounds or meeting with the manager on the unit every Thursday. The meetings were interdisciplinary. Occasionally, a team member would identify a potential participant.

After qualified participants were identified, each potential participant was visited that day and introduced to the study. The letter of invitation was given to all participants. The investigator met with the participant and caregiver, when available, in the hospital to explain study details, confirm that all inclusion criteria were met, answer any questions from participants and caregivers, review the written consent, and set a day and time within seven days to visit the participants at home. When the caregiver was not present, the same process used at the bedside with the patient was used for the caregiver in the home before the study was initiated. Identifiable, confidential information was stored safely. The investigator, director, or designee continued to identify additional participants, as needed, until the study was completed. The investigator telephoned 
participants to confirm the date and time of the home visit. Any participants who declined to participate in the study were accorded a polite expression of thanks. The screening process occurred at the beginning of the interview to ensure the older adult and informal caregiver met study criteria. If the participants were found to not meet all inclusion criteria, they were politely excluded from the study without continuing with signing consent or initiating interview questions.

After a slow recruitment process, the research director reached out to other unit managers. The investigator met with the new manager on another unit who helped to identify potential participants. To track the inclusion and exclusion participants, the investigator reached out to a staff person who would print the patient census list. The list provided information on potential participants such as room number, name, date of birth, sex/age, number of days hospitalized, and admission date.

The most frequently occurring exclusions included being non-English speaking, having had a stroke or mental instability, living alone or being homeless, living more than 25 miles from the hospital, having no caregiver, or declining to participate. Participants who qualified for the study had different reasons why the interview did not occur, such as not telephoning the investigator as agreed, declining when a phone call was made to setup a home interview, not answering the phone after their discharge, family dynamics (e.g. too many children in the home where privacy could not be assured), being undecided in the hospital, being discharged before they could be contacted, and being out of the room or sleeping when contact was attempted.

Data collection procedures. A semi-structured interview was used to guide the inductive logic, emergent strategies and explicit analytics for this study (Charmaz, 2012). 
The investigator gathered first-person narratives of participants' perspectives on discharge instructions provided while in the hospital and the implementation of the discharge instructions after returning home. The hospital discharge instructions provided a synopsis of the patient's history, treatment plan, reconciliation of new and current medication (s), self-care and connecting with healthcare professionals in the community. Informal caregivers were interviewed separately to minimize either participant from influencing the responses of the other. The discharge instructions were not obtained to maintain patient's confidentiality.

The interviews were conducted in the homes of the participants, face-to-face, using open-ended questions to allow discharged patient participants to readily provide information on their experience of the discharge instructions. The participants were informed the interview was going to be tape recorded and planned for 45-60 minutes. Participants were notified when there were 15 minutes remaining to avoid ending the conversation abruptly.

The investigator was sensitive to immersing herself into the discharged patient and caregiver participants' experiences by storytelling, respecting all participants' experiences (Holloway \& Wheeler, 2010). The investigator's communication skills included listening, observing, asking open-ended questions, clarifying, paraphrasing, assessing non-verbal cues, using silence, and using closed-ended questions carefully (Grover, 2005; Holloway \& Wheeler, 2010). The investigator wrote in-depth memos after each session. All interviews were digitally recorded and later transcribed. The investigator initiated coding and constant comparison that developed into categorizing 
codes. Ultimately, the goal was to generate themes that answer the research question and a theory developed (Charmaz, 2014).

The questions asked drew on intensive, informational, and investigative interviewing strategies. Using a grounded theorist approach, the interview approach may change as the study develops, taking into consideration that questions needed restructuring based on interactional style, cultural differences, and social economic conditions. The interview moved in unexpected directions, so the investigator remained fluid and open to responses (Charmaz, 2014).

Intensive interviewing generated data for the research study and explored research participants' perspectives on their personal experience with discharge instructions. In the face of any concerns, such as with patients' or caregivers' anxiety due to the interview process, the investigator stopped the interview immediately and explored if the interview should stop or if the intensive interviewing could continue (Charmaz, 2014). Intensive interviewing is important in grounded theory to elicit patients' and caregivers' experiences related to discharge instructions with skill, style, and sensitivity.

The investigator created the right climate for the interview, encouraging the participants to talk while she paid close attention to body language, gaze, and murmurs of "uh huh's from participants. Memo-writing documented non-verbal cues that could not be transcribed such as restlessness, fatigue, and side effects due to medication. The interview questions used (see below) were meaningful open-ended questions so patients and caregivers felt able to share their hospital experience. The investigator respected all participants' culture, traditions, and the situation of the participants by letting the patient and caregiver set the tone and pace. The investigator anticipated that questions could 
change and become more refined as the interview progressed to increase understanding of the issues and to continue engaging the participants.

Informational interviews sought to obtain the following information:

1. Participants' characteristics such as race, ethnicity, gender, age, education, profession, occupation, income level, and marital status.

2. Hospital discharge date.

3. The process by which both participants in the dyad obtained the discharge instructions.

4. Roles of health professionals who were involved with providing discharge instructions, such as nurse, pharmacist, physician, discharge planner, and others, if known. No names or personal identifying information about healthcare professionals were collected.

5. Whether the patient or caregiver had reviewed the electronic medical record while hospitalized.

6. How the participants in the dyad may have implemented discharge instructions.

7. A picture was taken of the location where the discharge instructions were placed when available and the patient was agreeable.

8. Perceived barriers and facilitators to implementation of discharge instructions.

The goal of the investigative interviewing was to uncover hidden actions or intentions of participants regarding discharge instructions during or after discharge from the hospital. Participants were asked these questions in separate interviews. To avoid yes 
or no questions, reframing the dialogue helped to elicit more in-depth responses (see appendix A).

Initial questions included:

1. At what point during your hospital stay did you feel you were being prepared to go home (be discharged)?

2. During the discharge process, what went well? Is there anything you can think of that did not go well?

3. Did a nurse come (or will come) to your home or did you receive a call from a nurse? What did the nurse tell you to do at home to take care of yourself?

4. Now that you are home, how do you feel that you have adjusted?

5. Have you had any change in your medications? Any change in your diet? How are you handling these things: this question will be patient specific based on the discharge instructions received [i.e.: wound, catheter, etc.]) (Patient and Caregiver)

6. Have the hospital discharge instructions been helpful? If so, how have the discharge instructions been helpful?

7. Are there parts of the hospital discharge instructions that you have done differently than was suggested or did not agree to? What have you done differently and why?

8. The hospital discharge instructions indicate you needed to follow up with the doctor. Have you scheduled an appointment yet? (ask specifically when is the appointment date and time, if patient stated an appointment 
was made to see PCP or a specialist) Do you foresee any problems related to transportation, financial issues, or other concerns/issues you would like to share that have not been brought up today?

9. Did you review your medical record while in the hospital?

10. May I take a picture where you stored your discharge instructions that you were given in the hospital and any that you have been given since you came home?

Based on subjective or unclear statements and non-verbal cues from patients or caregivers, the investigator refocused questions to promote clarity and meaning. Grounded theory guides the methods of data gathering to advance emerging ideas. This means reframing certain questions to reveal different responses or to disclose additional information. Therefore, follow-up questions were asked and were designed to elicit any underlying thoughts or behaviors that may contribute to developing a grounded theory specific to the study topic. When appropriate, the investigator stopped and explored a statement for in-depth description, redirected the participants, or asked about emotions that arose during data collection (Charmaz, 2014).

To end the interview, summary questions were asked to allow the participants to reflect or elaborate on previous information discussed (Charmaz, 2014). These questions included the following:

1. Is there anything else you can think of that would help me understand how you used or didn't use the discharge instructions?

2. Is there anything else you would like to share?

3. Do you have any questions you would like to ask me? 
Memo-writing, also known as informal analytic notes, serves to document analytic work and productivity when coding. After the interview, the investigator documented nonverbal actions and behaviors that were unable to be recorded by patients or caregivers during the interview.

To accomplish the aims of this study, the questions were reevaluated after each interview to assure rich data were obtained from the participants. In the first two interviews, the participants did not tell their own stories. The participants' answers lacked rich responses and the natural flow of information. They did not elaborate after answering the question only to wait for the next question despite the researcher asking probing questions. From this analysis, the questions were framed to increase a rich response from the participants, so a natural flow of rich data would occur.

Data management. A transcriptionist at https://www.gmrtranscription.com/clientlogin.aspx transcribed the digitally recorded interviews. Once the transcripts were transcribed, the investigator manually coded the data in Microsoft Word and used Microsoft Excel to store the coding data.

\section{Data Analysis}

For the purpose of this dissertation study, only patient participant data were analyzed. The caregivers' data were not analyzed at this time. The goal of the proposed systematic data analysis was to generate codes, complete constant comparison after each interview, and develop categories coding that were processed and analyzed. The steps are outlined below and began immediately after the first interview. An integrated central theoretical framework, also known as an emergent theory, developed leading to a theory grounded in the data provided by the interviewees (Charmaz, 2012). 
After the first interview, the investigator began the analytic process through some reflective thoughts and questions. The following questions were considered by the investigator (but were not asked of the participants) to direct future interviews and to revise, broaden, and ask more open-end questions

1. How did the participants view the discharge instruction from the lens of educated verse uneducated participants and those newly diagnosed or with a long-term illness?

2. Did any financial concerns exist but were not explicitly discussed?

3. Were there any concerns about home environment needs such as cooking?

4. Were there any concerns related to family members, friends, caregivers?

5. How did the participants feel about returning home?

6. Were there any stressors, fears, and/or worries not expressed that can affect how a participant views and carries out the discharge instructions?

7. Who exhibited dominance if that is not expressed but observed: discharged patient participant or caregiver participant?

\section{Initial Data Coding}

Charmaz (2012) stated that coding begins with an inductive analytical process and moves toward deductive reasoning, asking the what, when, and how questions. The investigator asked analytical questions to explore statements to increase understanding and interpretation of the data. The comparative method was used at each stage when analyzing the data.

In coding the data, there were two initial phases: first and second cycle coding. In analyzing the data, the first cycle coding process was created (Saldana, 2016). The first 
cycle coding identified the most significant or frequently reoccurring codes. As this process continued, the first cycle coding was sorted, synthesized, organized, and integrated. The research data were studied in fragments: words, lines, segments, and incidents. The data for the first cycle that were coded came from field notes as well as interviews. Line-by-line coding and recoding was done and eventually, the investigator moved into second cycle coding. In the second cycle coding, the analytic data developed to formulate a sense of the participants' stories, statements, and observations (Charmaz, 2014, Saldana, 2016).

Charmaz (2012) recommended the use of gerunds to see processes not readily observable to the investigator. Gerunds are words ending in "ing". They are used in the process of grouping categories that brought the investigator into the data (Charmaz, 2014, p. 394). Gerunds give action to the data and identify processes that allowed the investigator to stick to the data, gave direction within the data, and improved comparisons between data. Use of gerunds brought the participants' meanings, actions, and world to life within the categories. Gerunds helped to forestall the investigator from interjecting her experience instead of that of the participants.

\section{Concurrent Data Generation and Analysis}

After each interview, the data were transcribed and coded before the next interview occurred. In concurrent data generation and analysis, the investigator collected data from an initially purposive sample. The initial coding was done before more data were collected or generated. This part of the process differentiates grounded theory from other types of research design. 
The transition to the second cycle methods required classifying, prioritizing, integrating, synthesizing, abstracting, conceptualizing, and theory-building toward categorizing codes to generate themes that answer the research question until a theory developed.

\section{Memo Writing}

Memo-writing began with the first interview. Memo-writing helped during the coding process and added richness to the analysis. Memo-writing is a crucial method in grounded theory. These notes reflected the investigator's thinking and were designed to document questions, clarify what to observe including nonverbal and paraverbal interactions, and move the analytic processes forward (Charmaz, 2012). Memo-writing was important data to analysis along with the interviews (Appendix B).

\section{Theoretical Saturation}

The investigator committed to estimating the number of patients to be interviewed during the study. The number of patients was dependent on the conclusion of data collected after the data were saturated with no additional data leading to the identification of new categories. The investigator elected, with empirical confidence, to stop collecting data and determined that a core category of rich data had been obtained and that an analysis could be completed. This was the point at which the investigator began to formulate theoretical categories and developed a theory. Full theoretical saturation occurred that warranted the end of data collection (Charmaz, 2014).

\section{Theoretical Codes and Categories}

As data collection progressed, theoretical categories did not emerge until after considerable analysis, puzzling, and nascent ideas (Charmaz, 2014). Puzzling information 
or pieces of data or quotes that were unresolved led to follow-up interviews to learn more specific details from the participants. Bracketing is a method used to mitigate preconceptions regarding puzzling information that arises during the research. The investigator risked making self-assumptions that potentially could have tainted the research and decreased the rigor of the study. In this study, bracketing was necessary due to the investigator's extensive background in home healthcare.

\section{Theoretical Sensitivity}

As the investigator became immersed in the data, personal insight emerged in the area investigated. The investigator can enter the field of inquiry without concern for his/her own predetermined thoughts biasing the research. A theory emerges from the data. As the intellectual belief emerged from the participants' perception as to how they implemented the discharge instruction, the investigator did not lose sight of or commit exclusively to a preconceived theory, such as how a patient or caregiver responded to implementation of the discharge instructions (Charmaz, 2014).

\section{Theoretical Sampling}

This process helped to retrace steps previously taken or helped to guide the investigator in new directions. This process was effective when the tentative categories and emerging categories had incomplete ideas. To gather additional information, the investigator collected more data that focused on the category and improved the analytical process by analyzing the interview before the next interview occurred. The benefit of theoretical sampling advanced the analysis and helped advanced the analysis process (Charmaz, 2014). 


\section{Theoretical Sorting, Diagramming, and Integrating}

In grounded theory, use of theoretical sorting, diagramming, and integrating guides the investigator toward theory development (Charmaz, 2014). In this study, diagramming, use of maps, charts, and figures helped create a visual image of the categories and their relationships and provided further direction for the analysis.

\section{Protection of Human Subjects}

This research was conducted on human subjects and followed the fundamental rights of human dignity, protection, and safety and minimized any harm to the participants by respecting the participant in their home (Markham, \& Buchanan, 2012). The principles of good ethical practices and protection of human subjects were followed from inception to completion and dissemination of this study (U. S. Food and Drug Administration [FDA], 2014). In adherence with ethical consideration for scientific research, permission to conduct research involving human subjects was obtained from a Hospital Internal Review Board (IRB) and the University of San Diego IRB that reviewed and approved the study (see Appendix C for University of San Diego Internal Review Board approval only. Per University protocol, the hospital IRB paperwork is not included in this dissertation. IRB oversight was obtained before starting this study).

\section{Informed Consent}

The informed consent was used to ensure that all the research principles satisfied moral, ethical, and legal issues, and that the human subjects were protected through anonymity and confidentiality. All participants signed an informed consent to participate in the study after the investigator explained the study to patient/caregiver dyads, so both parties could make an informed decision about the nature and consequences of the study. 
The investigator assured the participants' privacy, and confidentiality. Participants were assured that anonymity of data would be respected and protected by coding instead of using their names and not sharing any participants' information. Participants had the opportunity to ask questions and the investigator gave the participants freedom of choice to participate in the study without coercion. Participants received in writing the purpose and aims of the study and made the choice to participate voluntarily. Data collection procedures complied with the United Nations Universal Declaration of Human Rights, the Nuremberg Code, the Belmont Report, and the Declaration of Helsinki, in which participants are required to be informed of the purpose, duration, methods, and risks of the study (Christians, 2011). The participants or caregivers did not experience or risk any discomfort sharing their discharge experience. The investigator showed respect and concern by asking participants if they would like to stop for a moment or end the interview. None of the participants elected to end the interview and there were no physical risks as a result of the interview. However, if the participant needed medical care during the interview, the investigator instructed the participants or caregivers to contact their primary caregiver or to call 911 . All personal data obtained was de-identified to maintain confidentiality. The participants were informed that none of their de-identified information would be shared except with the investigator's committee members and editor. All data were secured on the investigator's personal password-protected computer to ensure confidentiality of the data.

\section{Trustworthiness}

The investigator's intent was that data collection and theory development processes would be trustworthy. To accomplish such a level of rigor in this qualitative 
research, the work was completed with a thoroughness and level of competency so that the findings had meaning from the stories of human experience (Holloway, \& Wheeler, 2010). The researcher conferred with the dissertation chairperson throughout this process to ensure trustworthiness. There are four criteria in qualitative research that are used to evaluate trustworthiness: a) credibility; b) dependability; c) confirmability: and d) transferability (source).

Credibility. The investigator was intimately familiar with the topic, which contributed to the results being believable. The investigator interviewed participants and the digital recordings were transcribed verbatim as to what the participants' shared. Memo-writing was detailed and extensive. The investigator was careful to not interject her own thoughts and preconceptions during the study by use of questions during the interview, awareness of investigator background in home care admissions, and bracketing (Holloway, \& Wheeler, 2010).

Dependability. The investigator accurately captured important information and there was no attempt to generate misinformation in this study. The investigator collected and analyzed the data using participants' words and written memos in the analysis. An audit trail was used to demonstrate how all thematic conclusions were achieved. The investigator was supervised by her dissertation chair during the data analysis (Holloway, \& Wheeler, 2010).

Confirmability. The investigator acknowledged that past knowledge in home healthcare brought a distinctive perspective to the study. By acknowledging such experiences, the investigator's subjectivity increased constant awareness and selfreflexivity so that no prior beliefs substantially biased the results. The investigator 
maintained value neutrality during the study (Holloway, \& Wheeler, 2010). The goal of this study was to represent the participants' voices and not that of the investigator by capturing the participants' words, in-vivo.

Transferability is not as clear as in quantitative research where the sampling of subjects is purposeful. In qualitative research, such as grounded theory, the sampling is theoretical. Therefore, the knowledge obtained from this study provided a "greater body of knowledge" and can be transferred from this study to assist in the development of future studies and possibly to similar situations or individuals (Holloway, \& Wheeler, 2010).

\section{Summary}

Chapter 3 discussed the grounded theory method as interpreted by Charmaz. Her approach is to interact with people to construct a grounded theory. The investigator and participants are part of the world where data are collected. Constructing grounded theory starts with gathering data from interviews and ends by reflecting and writing an interpretation resulting in theory formation. The process unfolded after an encounter with participants. Memo-writing initiated the process of integrating those notes later into a diagram as concepts developed toward a theory. Theoretical sampling elicited new data as the process ebbed and flowed. As new data were collected, this information enriched the collection process to support theoretical categories. Chapter 3 discussed grounded theory methods as a systematic way of collecting data, analyzing qualitative data, and moving toward constructing a theory.

Chapter 4 presents pertinent patient findings after interviewing patients and analyzing their data. Although both patients and caregivers were interviewed, only the 
patient findings are included in this final dissertation. Chapter 5 discusses the findings, study strengths and limitations, implications for practice, and future research. 


\section{Chapter 4}

\section{Results}

This chapter presents the findings of in-depth, semi-structured interviews conducted with older adult patients. All participants were interviewed in their homes and had been discharged within the previous seven days.

The primary aims of this study were to:

1. Describe how discharge instructions were implemented in the home setting by adults 65 years of age and older and their caregivers following an acute care hospital discharge.

2. Identify perceived facilitators and barriers to implementation of discharge instructions among older patients and their informal caregivers.

\section{Participant Characteristics}

Ten older patients participated in the study. Most of the participants lived near the hospital or in surrounding communities, all less than 25 miles from the hospital. The patients' mean age was 70 years old and $60 \%$ were female $(n=6)$. On average, participants stayed in the hospital five days (Table 1). 
Table 1

Patient Participant (P) Characteristics

\begin{tabular}{lccclc}
\hline $\begin{array}{c}\text { Patient } \\
\text { Code }\end{array}$ & $\begin{array}{c}\text { \# of days } \\
\text { hospitalized }\end{array}$ & Age & $\begin{array}{c}\text { Miles b/t } \\
\text { hospital } \\
\text { \& home }\end{array}$ & Race/Ethnicity & Gender \\
\hline P1 & 5 & 78 & 10 & African American & F \\
P2 & 6 & 77 & 1 & Caucasian & F \\
P3 & 4 & 76 & 12 & African American & F \\
P4 & 3 & 84 & 5 & Hispanic & M \\
P5 & 4 & 69 & 4 & Filipino & M \\
P6 & 3 & 81 & 3 & Caucasian & M \\
P7 & 10 & 69 & 3 & Filipino & M \\
P8 & 3 & 80 & 1 & Filipino & F \\
P9 & 4 & 85 & 3 & Caucasian & F \\
P10 & 3 & 71 & 5 & Filipino & F
\end{tabular}

\section{Discharge Instructions}

While the purpose of the study was to understand how discharged patients implemented their discharge instructions from the data analysis, it was quickly realized that discharge instructions were not a high priority in resuming participants' post discharge lives. All participants acknowledged they received written discharge instructions and said the discharging nurse discussed, at a minimum, medications to be taken at home. Returning to home life actually superseded most instructions provided at the time of discharge; therefore, returning to home life evolved as a primary focus of the study findings. The results of the study will be addressed in each of the study themes below. And, when relevant, discharge instructions are placed in context of the theme. 


\section{Study Themes}

A number of themes emerged from the study data. The main themes that emerged from the participants' data included Transitioning Hospital to Home Process, Knowing Their Life Was Resuming Again, and The New Normal. Several subthemes were also identified that supported each of the main themes. See Figure 1.

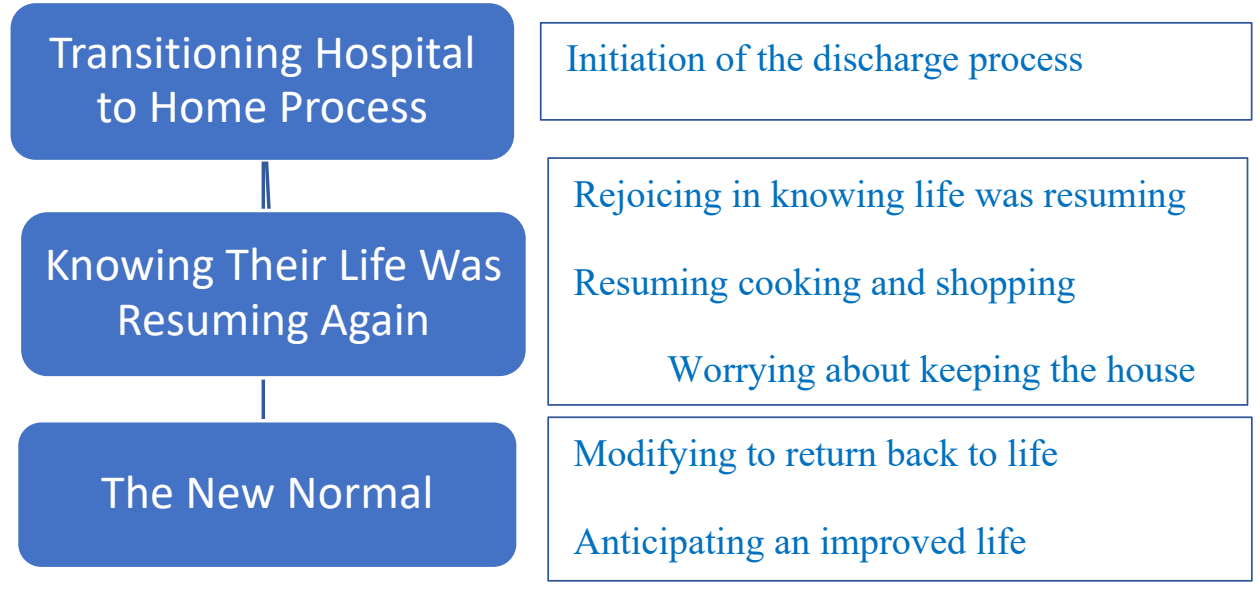

Figure 1. Summary of Study Themes

\section{Transitioning Hospital to Home Process}

The first main theme, Transitioning Hospital to Home Process, emerged from data that the discharged patients shared about their experience with the hospital discharge process. All participants reported the process began with a physician and finished with a nurse. Two additional subthemes that emerged were initiation of the discharge process and attention-distraction.

Initiation of the discharge process. Most participants recalled receiving the discharge instructions, verbal and written, but perceived the hospital physician as the catalyst to initiating the process. The process started with the hospital physician entering the participant's room and ended after the nurse visited. P7 stated that "When the doctor 
came in one afternoon and told me that I can go home...not my primary...this is the hospitalist... I wait for my nurse, she got the paperwork.” P2 reported Um, I got the authorization from doctor that I could go. And then the - the lung doctor came in and she said I was fine to go, and then Dr. L. and then, you know, they turn it over to the - the nurses and whoever's in charge, and they do the paperwork and everything... I just had to sign my name pretty much.

Both P7 and P2 expressed a level of understanding of the discharge process and had anticipated the impending discharge from the hospital.

However, not all participants clearly understood the discharge process. Sharing thoughts that he had in the hospital, P6 said, "They did the surgery on one morning, and I spent that night there. And I sorta felt like I thought maybe I was ready to go when I woke up the next morning." After the physician stopped by to inform P6 that he could go home, he perceived leaving the hospital promptly by saying, "Before he came in, I had some questions in my mind, but he answered the questions and then said, Well, then I'm - as far as I'm ready to go." P6 expressed disillusion the discharge was delayed. He mimicked the moment of how impatient he was because he had to wait while "getting the word out to the staff that I would be departing" was part of the process by rolling his eyes in exasperation.

Participants shared there was a waiting period for the nurse or "someone" to complete the discharge. When questioned further, participants did share that following the physicians, the nurses brought in the written instructions. Some participants acknowledged they did not bother to ask questions or clarify information during this time 
when the nurse was present. This was a time that participants seemed to be distracted off and on, thinking of life outside of the hospital.

Attention-distraction. A hyphenated concept, attention-distraction was a study sub-theme that represented a state of consciousness experienced by participants that explained a time when they were seemingly attentive to the nurse but admitted they were also distracted by other impeding thoughts. Participants reported this was primarily the time to gather their belongings to leave the hospital and they focused on that process when discharge instructions were being given. Other distractions occurred and will be elaborated in another section.

During his in-home interview, P6 reported that he may not have fully comprehended the purpose of the discharge process or discharge instructions, sharing the following: "Sort of, uh, I don't know what's going on here? What are we waiting for?" He viewed the discharge process as "sort of getting the last-minute discharge instructions... just hand me this paper." He wanted a quick departure, sharing "I was able to walk out of the hospital, but I know it's hospital procedure to always take a patient out in the wheelchair."

P6 wanted to go home but once home was concerned about his medications. He said, "I didn't think to ask all the questions I should have...I have an awful lot of medications I take...I get back on my regular medications?” As an engineer, being organized with his medications was very important to him. Even when he asked the nurse a question about his medication, he admitted he did not listen to the answer. He recalled that the nurse instructed him to resume his medications "Soon - soon as you leave." However, 24 hours after discharge, P6 was still pondering what exactly the nurse said and 
when to resume his regular medications. He could not recall if the nurse said, "last night or this morning." He admitted grilling himself with no assurance of what was the right answer. He proceeded to quiz himself further on how to take a new over-the-counter medication. During the interview, he divulged his mind was on returning home and he was not paying close attention to what the nurse was saying. He also disclosed he had not reviewed the discharge instructions since arriving home. Instead, he spent time during the interview showing how systematically he had organized his medications. The participant read the instructions from the nurse to the interviewer. He was surprised to read he was supposed to take his next dose of medications last night. He further read the details of how to take the medication how to administer the over-the-counter medication. He added he should have read the instructions after arriving home.

Some patients were thinking about many things while the nurse was providing discharge instructions. P1 stated the nurse came in, "She came in and explained the whole... then, you know, gave me the chart and told me to review it myself when I get home, and if there were any questions, you know, feel free to give them a call." In her home, P1 had placed the discharge instructions in a recliner chair pocket but had not reviewed them since discharge. P1 expressed she was engrossed with thoughts about her home because of the holiday, resuming her medications, finances, and following up with her physician because she did not like the medication change made by the hospitalist.

Finally, some participants admitted they were preoccupied with a higher power during the review of the discharge instruction. Specifically, four of the 10 participants reported leaning on a spiritual strength or calling upon a higher spirit that was leading them home. For example, during the discharge process, P9 expressed a disengagement 
because she had a belief a higher power would lead her home. P9 believed her prayers during hospitalization alleviated her fears and resulted in positive results. While hospitalized, she thanked Jesus for receiving positive feedback on her health, saying, "I did CAT scan and did the rest, but I'm not - I'm alive, so I was in that thing, and then, I was just praying to Jesus... it came from the Holy Spirit told me what to do." Even at discharge, P9 believed the discharge papers were not as important as reading her bible, reporting, "she (the nurse) didn't even discuss anything with me and she just told me read it because she saw me reading my bible, [chuckles] so she (nurse) said, 'Just take it home' and review... She just gave me all the papers." When questioned if she had read the discharge instructions since her discharge, P9's response was, “I'm going to - to my doc - family doctor... I'm kind of stubborn." She had not read the discharge instructions since being discharged.

In summary, all participants acknowledged the discharge process started with the physician and was completed by the nurse. Participants experienced a preoccupation at the time the discharge instructions were provided due to an attentive-distractive process in which, while being physically present, they had other thoughts on their mind. Once home, while some participants viewed the discharge instructions as informative, most indicated they would not have prolonged their hospital stay to concentrate on the discharge instructions. Participants were interested in discussing the discharge instructions but in the context of returning home, which was their priority.

\section{Knowing Their Life Was Resuming Again}

Reviewing the discharge instructions after arriving home was also not a patient priority. Instead, most patient participants disclosed their desire to resume life and 
"business as usual," never referring to their discharge instructions. Four subthemes reflected this focus and included rejoicing in knowing life was resuming, resuming cooking and shopping, worrying about keeping the house clean, and resuming socializing. Resuming their life meant the participants desired to restart daily activities, but for some it was only to the degree possible. Overall, the hospital admission had been perceived as necessary, but the desire to return home at a pre-hospital level of function was shared by all participants. Participants described departing the hospital as a positive step to picking up where they left off with their lifestyle.

Rejoicing in knowing life was resuming. Interestingly, many participants expressed a spiritual component to resuming life after hospitalization. For example, returning home was a time to rejoice for P8. Her strength came from her grandchild and through prayers. She said, "The prayers all give, I'm dancing, dancing and ...I have the grandson, oh, I can hear, I can hug her." Similarly, P10 said that having God in her life gave her strength and returned her home. She had lived with asthma since childhood, “since I was a teenager" and added "I'll be very lucky and so, God is good, even though I'm sickly." She reported that her life has been good with God. She did not believe she would live past age 50 . Believing she was very compliant with her medication and activity regime, she stated that she did not need to review the discharge instructions to confirm if any medications had changed. She stated "if it wasn't for God" she would not be alive today. She expressed her belief in recovering and that restoring her life was better accomplished at home. She added, 'I feel like I'm healthy, still my wheezing light wheezing is still there" but expressed happiness she was home and with her family. 
Resuming cooking and shopping. Post hospitalization came with the need to recuperate despite participants' desires to resume a familiar life-style and some of their normal daily activities. As would be expected, some participants expressed a desire to eat food that they prepared over the hospital food. As an example, being discharged was an opportunity for P9 to resume eating her own food. Leaving the hospital was also her opportunity to go shopping for food supplies. She said, "after we were done picking my medicine uh, went grocery shopping."

Life at home was in the kitchen for P1. The hospitalization took her away from her normal pleasure in life cooking. However, after her discharge her spouse barred her from the kitchen. He instructed her not to resume cooking. During the interview, she shared, laughing, how the other day she waited for her husband and daughter to leave the house for an appointment. She described how she watched them drive off and headed into the kitchen. She said, "I put on a pot and started making soup." She expressed how her home life was interconnected with cooking and did not bring up the discharge instructions until the investigator specifically asked to view the papers. She had to think momentarily where she had even put them.

Worrying about keeping the house clean. Even with an expressed decrease in strength or greater physical limitations for participants, returning home involved resuming their role in keeping their homes clean. A number of participants recognized their chronic conditions were affected by the condition of their homes and so this was an important parting of resuming their life.

As an example, P10 expressed being fastidious about keeping her house clean. She expressed preoccupation with the condition of her home since dust had to be kept at a 
minimum due to her chronic asthma. She shared that a dusty home would likely cause a respiratory exacerbation, disrupting her current goal of resuming her pre-hospitalization strength and physical status. At first, since she was too weak to resume housecleaning, she felt forced to delegate the housekeeping duties to her spouse and brother, "because I'm really, really a clean woman...because I don't really want dusty, so he (spouse) did for me." However, even though her husband dusted all the time, she could still "smell the dust." She struggled with a compulsory desire to do the dusting herself. While not completely satisfied with the dust situation, she described herself as having to maintain her role as an overseer to assure her house was cleaned properly.

Resuming socializing. Participants reflected on socializing as part of resuming their previous lives. Some were ready to jump back in to socializing while others realized this would take more time. For P8, family socialization was important. Life without her grandchildren and walking daily in her garden left her feeling her life was nonexistent. She was exuberant to renew her bond with her family. For the interviewer, she demonstrated walking in her garden and saying, "I can hug my doggie here, grandchildren, and I can walk around there in my garden in the morning. Oh, I can, I can see my flowers." She was enthusiastic during the interview.

Not every participant felt ready to resume full socialization. As an example, P10 reflected,

...be careful now in trying to avoid all this stuff that me and my husband used to do - used to go out more often, and yeah, because I notice it myself, because yesterday, because I don't want to stay in the house the whole day, and I said, oh, I think I feel a little bit better today, so can we go somewhere? We just went 
somewhere for a little bit, eat my lunch, and when we come back, honey, I don't feel good again.

She found attempting to resume socializing outside of the home with her spouse was too taxing.

To summarize, for participants, leaving the hospital meant resuming their previous life in the home that included their routines with family connections. Participants expressed pleasurable activities such as cooking, going shopping, and socializing were most meaningful to them. Many voiced that a recovery period was needed but were thankful to be back in their home environments. Discharge instructions were not a focus of the participants and in fact, some could not even locate the instructions.

\section{The New Normal}

Finally, a third main theme, the New Normal, emerged with two subthemes that included modifying to return back to life and anticipating an improved life. Each of the participants shared they returned home with an existing or new chronic condition and acknowledged a bodily physical awareness (e. g., physical weakness and loss of strength) as part of their developing a new normal. Discharge instructions were not referenced as part of these discussions.

A number of participants viewed their post-hospitalization life as a new normal after an exacerbation of a previous condition. Participants viewed the hospital as a place to correct their acute physical symptoms so that life could continue, even if it meant living to their full potential with a chronic condition. 
Other participants reported that returning back to their former life would likely take time because living with their new condition would need to be viewed as part of living their daily life.

Modifying to return back to life. This theme reflected making adaptations to return back to their home life. Some participants realized that an acute condition had required a hospitalization and would also affect their ability to resume full functioning quickly. As an example, before hospitalization, P2 delayed seeking care after experiencing significant symptoms related to a new diagnosis of congestive heart failure (CHF). She down-played her symptoms hoping they would subside. However, now she shared that she did indeed know something was wrong, saying "I woke up one day and I just - I couldn't barely function, I could barely function. My husband had to sort of take me, you know, to the bathroom, and walk me around, and he got really concerned. So then, he just took me up to the hospital."

Following hospitalization, P2 stated that returning back to her former life was possible because of her husband's current support and help. "The cardiologist told me I could get back to my normal activity, just, you know, not jumping around so much, but... I plan on going out and start walking. I'm not going back to my aerobics class yet." Now at home to recuperate, she expressed she must modify how she will be living at first in order to resume her life.

Anticipating an improved life. For a number of participants, the hospitalization brought awareness of their physical condition with anticipation of improved outcomes afterwards. P9 described her new normal as living with her chronic conditions, hypertension and diabetes, by expressing an increased awareness of her body. As she 
strove to improve her life she said, 'I'm aware of myself, now, every time I feel something in my body that's not normal." She now felt knowledgeable about her symptoms even though she had delayed seeking medical attention initially. Her new normal will be to "do little errands here and there." Whether newly diagnosed or living with chronic health problems, participants expressed increased consciousness about current restrictions to their lives and sounded accepting of delays that could possibly limit a quick return to an improved life.

In summary, participants returned home with residual symptoms that limited a quick resumption of their pre-hospitalization life. Participants reported they had to limit activities and now had increased awareness of symptoms to live with, with no mention of discharge instructions informing their thoughts.

\section{Summary}

The purpose of this qualitative grounded theory study was to gain knowledge about the implementation of the discharge instructions and any perceived facilitators and barriers. While infrequently used, the primary use of the discharge instructions was as a reference for medication administration. Most participants indicated that they did not attend to discharge instructions or even read them on returning home. Rather than discuss what they did or did not do with regard to discharge instructions, they described the discharge process and the areas of concern that they had on returning home.

Interestingly, patients did not perceive discharge instructions as highly important. As a result, they spoke very little about their discharge instructions. Some participants even had difficulty locating the instructions while being interviewed in their homes. Therefore, little was shared by participants about implementation of discharge 
instructions, including perceived facilitators of and barriers to implementation. The one study subtheme most associated with being a barrier to implementing discharge instructions would be attention-distraction, illustrating a time while still in the hospital that patients were seemingly attentive to the nurse but admitted that they were also distracted by other impeding thoughts. Overall, the discharge instructions were not viewed as a high priority during the interviews. Returning to home life superseded paying attention to the instructions given at the time of discharge and utilizing them at home.

Three main study themes did emerge and included Transitioning Hospital to Home Process, Knowing Their Life Was Resuming Again, and the New Normal. The first theme, Transitioning Hospital to Home Process was the initiation of the discharge process and an attention-distraction patient state described of the discharge process. All participants recounted the process was initiated by a physician and completed by a nurse. The second theme, Knowing Their Life Was Resuming Again, involved the developing awareness that, after discharge and returning home, their life was resuming again, and they needed to resolve concerns about resuming lifestyle activities that were important to them. The third theme, The New Normal, refers to another awareness, specifically, that physical adjustment after the hospitalization would not only take time but meant a new normal for them. It is anticipated the planned analysis of the caregiver data is required to generate a grounded theory.

Chapter 5 will summarize and discuss the study findings and its implications for practice and for future research. 


\section{Chapter 5}

\section{Discussion}

The findings of this study are consistent with the challenges many hospitals have encountered with the transfer of information during discharge instruction, implementation of the instructions in the home, and rehospitalization; simply, that discharge instructions are not fully implemented or never implemented at all. The study by Coleman et al. (2013) indicated the need for hospitals to identify patients at risk of poor understanding and implementation of the instructions. They suggested that instructions should be tailored according to patient's needs.

The primary results of this study represent the process of patients reintegrating back into routines at home. Three primary themes emerged and include Transitioning Hospital to Home Process, Knowing Their Life Was Resuming Again, and The New Normal. The first theme, Transitioning Hospital to Home Process, represents an awareness by patients that a discharge process did exist and that process was initiated by a physician and completed by a nurse. The second theme, Knowing Their Life Was Resuming Again, represents a developing awareness their life was resuming again now that they were back home. The third theme, The New Normal, specifically brings into focus that discharged patients were developing an awareness of their physical body and, as such, were adjusting back to life after the hospitalization but coping with restrictions that meant a new normal for them.

The discussion of study findings will include the salient points regarding the study themes and how these findings are related to other literature on the topic of transitions to home after discharge from a hospital. Specifically, the topics covered will be a) the 
delivery of discharge instructions, b) once discharged, the resumption of former lives, and c) the meaning of a new normal to discharged patients.

\section{Delivery of Discharge Instructions}

Being discharged from hospital to home requires the delivery of discharge instructions by healthcare professionals. The National Patient Safety Goals (NPSG) have a set standard that discharge instructions be provided to every patient. The NPSG 03.06.01.4 states that instructions should be in writing and a signature obtained from patients acknowledging the instructions were received before the discharge (The Joint Commission [TJC], 2019; Holland \& Hemann, 2011). NPSG.03.06.01 and NPSG.02.03.01 further state that health professionals are to maintain and communicate accurate patient information, including that health professionals are to report tests and laboratory results, the care for any treatments, and to assure the education is received timely (TJC, 2012; TJC, 2019). It is the role of the hospital nurse in the discharge process to communicate, reinforce, and connect hospital care in such a way as to bridge to an appropriate level of care in the home (Eaton, 2018; Falvey et al., 2016).

All participants in this study shared that they were provided with written discharge instructions. In fact, the hospital process utilized to inform the patient participants of the discharge was consistent and delivered according to the NPSG standards. Additionally, both physicians and nurses were involved in the process. From the participants' perspective, physicians began the discharge process. The patient participants in the study spoke clearly about the procedures that occurred at the time of discharge. This is similar to what has been found in other studies (Eaton, 2018; Falvey et al., 2016). 


\section{A Novel Sub-Theme: Attention-distraction}

Published literature, including research studies, has identified that communication breakdown can occur during the discharge instruction process (Peter et al., 2015). While reasons for this breakdown may differ, a novel explanation emerged from this current study. During questioning and subsequent data analysis regarding participants' understanding of the discharge instructions, the subtheme of attention-distraction emerged. This emerged as the result of a number of participants sharing an experience of drifting thoughts while the nurse explained the discharge instructions. They explained they were being attentive to the nurse; however, they drifted in and out of that attentiveness due to other intrusive thoughts. They were not engaged in the transaction.

Many of these distracting thoughts involved thinking about how they would be resuming their life at home or that they were grateful to a higher power for their situation. As a result of these distractions, participants were challenged to recall many aspects of their care such as diet restrictions or when to resume activities or medications. While other studies have reported such lack of recall surrounding these topics, none have provided an explanation such as the attention-distraction subtheme that emerged from this study (Albrecht et al., 2014).

It is important to note that even with the hospital following national regulations, communication started to breakdown as the attention-distraction evolved, most likely unbeknownst to the health professionals. In addition, participants reported they did not read the discharge instructions at home, had poor follow-through with healthcare providers, and did not completely understand their medication regimens. Again, similar ideas were found in prior studies but with no link to possible underlying causes 
(Costantino, Frey, Hall, \& Painter, 2013; Eaton, 2018; Franklin, \& McCoy, 2017).

Therefore, more research is needed to investigate the diminished understanding and lack of follow-through in discharge information with patients in the context of a possible attention-distraction phenomenon.

\section{Resumption of Former Lives}

There is evidence that some older adults can be successful in resuming their former lives after discharge. Published research documents that this happens when discharged patients a) do the right thing to avoid complications after discharge, b) move from a more dependent state to a more independent state when able, and c) become reinvigorated in life through personal experience and the contribution to others in their life (Berg, Zwisler, Pedersen, Haase, \& Sibilitz, 2013; Bontje, Asaba, Tamura, \& Josephsson, 2012; Neiterman, Wodchis, \& Bourgeault, 2015).

While all study participants understood their hospitalization was necessary; not unexpectedly, they were interested in resuming their lives once they were home. So, after receiving the news of their discharge, all the participants shared they were ready to go home and to resume their lives. Once home, resuming their lives primarily focused on resuming activities around the house and beginning to socialize again. Bontje et al. (2012) reported that patients returning to independence and regaining their energy as they recovered resulted in the ability to resume daily activities.

In this current study, a number of participants shared a reluctance on the part of their caregivers to allow them to resume activities once home. Other studies report a similar concern explaining the caregivers' rationale was related to patients' weakness and 
slow recovery following discharge (Berg et al., 2013). This line of inquiry will be followed when the caregiver data from this study is analyzed in the future.

Socialization is deemed equally important in resuming one's life post discharge (Neiterman et al., 2015). Patient participants' social needs were just as important as their medical needs. There may be numerous opportunities to assess socialization needs while patients are in the hospital that may lend to incorporating strategies to assist them in resuming their socialization.

\section{A New Normal}

Most shared their need to resume life as it was before the hospitalization.

Evidence supports that discharged patients will focus on basic needs such as sleeping and eating in order to recuperate and even to avoid a readmission (Karlsson, Bergbom, Ringdal, \& Jonsson, 2015). This current study was helpful in elucidating beyond this short-term outcome (readmission) and revealed thoughts about a more transformative process a new normal. While one study supported this more patient-centered finding (Taule, Strand, Skouen, and Målfrid Råheim, 2015), additional evidence may be lacking due to the strong research focus on preventing hospital readmissions.

While being home was perceived to be a time to recuperate, a number of discharged patient participants reported a heightened awareness that their body would need to slowly adapt to a new normal. They had the desire to evaluate their ability to complete a task. Most had already been living with one or more chronic diseases and now they were entering into a new phase of their illness their new normal. They spoke openly about their loss of strength. 
Returning home meant a need to modify their lifestyles to successfully remain at home. They did not lose the sense of hope in adapting to their new normal and regaining control over their bodies. Many stated they had been living with their medical problems and now that the symptoms that caused the hospitalization were eliminated, they were positive life would resume for them, even if it meant a new normal.

\section{Study Limitations and Strengths}

Several limitations in this study surfaced and are acknowledged. First, recruitment of participants in the hospital was restricted by the severity of illness and frailty of certain patients. Second, as with all qualitative study results, the primary limitation is lack of generalizability of the findings (Charmaz, 2012). Finally, while data were collected from both patients and their caregivers in the home, for the purposes of this phase of the study, only the patient data were analyzed. Future plans are to analyze the caregiver data, triangulate patient and caregiver data, and if empirically supported, generate a grounded theory.

The major strengths of this qualitative grounded theory study included having access to a number of nursing units and attending stroke rounds for the recruitment process. In addition, listening to participants tell their stories about their discharge experience comfortably in their home environments resulted in rich data being collected and interpreted "in vivo," thereby decreasing bias in the study results.

\section{Implications for Practice}

It is critical that patients engage in self-care following a hospital discharge to prevent rehospitalization as well as return to a comfortable and self-satisfying state once home. The implementation of discharge instructions, especially for those living with 
chronic conditions, is documented in the literature as imperative (Cohen, 2015; Flynn \& Stevenson, 2018; Wilson, 2018). However, the written discharge instructions provided to patients in this study were not a priority for them. One strategy to improve the utilization of discharge instructions by patients may be by way of new technology. Moving discharged patients to electronic platforms outside of the hospital for personal home use through telehealth, wearable devices, smartphones devices, online portals, and applications may be a solution. There is enough evidence that older adults are now embracing technology (Wilson, 2018).

The importance of good communication cannot be underestimated and the novel subtheme of attention-distraction that was discovered during this study illustrates the breakdown of communication in the hospital setting. It is imperative that physicians and nurses communicate the discharge instructions to the patients. Distractions, either those in the environment or patient-generated self-distractions, should be assessed during the discharge instructions process before discharge occurs. A teach-back technique may be helpful for the discharging nurses in assessing if the patient has understood and retained the information. Teach-back technique has been used successfully in patients with heart disease (Peter et al., 2015). The same approach could be followed by home care nurses and case managers in the patients' homes.

Finally, chronic care managers are needed to support patients who are advanced in their chronic disease. The discharge instructions become more complicated and technical to comprehend as the disease progresses. Chronic care managers' knowledge and skills will be advantageous in helping patients adapt (Holland, Mistiaen, \& Bowles, 2011). 


\section{Implications for Research}

The reasons for participants' lack of understanding and non-adherence to the discharge instruction are likely complex. Future qualitative studies exploring the attention-distraction subtheme discovered in this study may be warranted. At some point in the future, the development of an instrument to measure patient attention-distraction may be warranted.

Both qualitative and quantitative studies conducted in the home setting should add to understanding the processes involved in patients transitioning from hospital to home. The home setting offers a "gold standard" for understanding the degree of implementation of discharge instructions as well as for the testing of interventions. Finally, studies utilizing technology at all points of the care continuum that might help to customize discharge instructions and reinforce the instruction should be pursued by the investigator.

\section{Conclusion}

It is the desire of every healthcare professional to actively engage their patients in the discharge process. The goal of this engagement is that patients will utilize their discharge instructions, reduce their chances of rehospitalization, and maintain an optimal quality of life. However, in this study it was determined that most patients did not utilize their discharge instructions; in fact, a number of participants could not even locate their discharge instructions in their homes. While there may be many reasons for this, one explanation discovered in this study involved a sub-theme whereby participants shared that while they would be initially attentive to the discharge instructions delivered by the physician and nurse, they would also find themselves distracted with other thoughts. 
When the healthcare professional attempts to deliver the discharge instructions, close attention to the patient's understanding is needed. This qualitative study points to the fact that more research with larger sample sizes is needed in order to understand how communication is perceived and what the effect patient perception has on the implementation of discharge instructions in the home setting. At least one other study concurs that more research is needed around communication during the discharge process (Eaton, 2018.) Patients who do not fully understand their discharge instructions will be left to their own interpretation of what to do following hospitalization. 


\section{References}

Abrashkin, K. A., Cho, H. J., Torgalkar, S., \& Markoff, B. (2012). Improving transitions of care from hospital to home: What works? Mount Sinai Journal of Medicine, 79, 535-544. doi.org: 10.1002/msj.21332

Albrecht, J. S., Gruber-Baldini, A. L., Hirshon, J. M., Brown, C. H., Goldberg, R., Rosenberg, J. H., ... Furuno, J. P. (2014). Hospital discharge instructions: comprehension and compliance among older adults. JGIM: Journal of General Internal Medicine, 29(11), 1491-1498. https://doiorg.sandiego.idm.oclc.org/10.1007/s11606-014-2956-0

Alberti, T. L., \& Nannini, A. (2013). Patient comprehension of discharge instructions from the emergency department: A literature review. Journal of the American Association of Nurse Practitioners, 25, 186-194. doi: 10.1111/j.17457599.2012.00767.x. Epub 2012 Aug 16.

Alper, E., O’Malley, T. A., \& Greenwald, J. (2019). Hospital discharge and readmission. Retrieved from https:/www.uptodate.com/contents/hospital-discharge-andreadmission

American Hospital Association. (2015). CMS proposed rule: Revising the requirements for discharge planning. Retrieved from www.aha.org/content/15/pshychall15dec04-callslides.pdf

American Nurses Association. (n.d.). Medicaid coverage of advanced practice nursing. Retrieved from http://www.nursingworld.org/documentVault/GOVA/Federal/FederalIssues?MedicaidReimbursement 
Bao, Y., Shao, H., Bishop, T. F., Schackman, B. R., \& Bruce, M. L. (2012). Inappropriate medication in a national sample of US elderly patients receiving home health care. Journal of General Internal Medicine, 27, 304-310. doi:10.1007/s11606011-1905-4

Barr, P. (2014). For baby boomers, health care where and when they want it. $H \& H N$ : Hospitals \& Health Networks, 88(12), 36-40.

Berg, S. K., Zwisler, A. D., Pedersen, B. D., Haase, K., \& Sibilitz, K. L. (2013). Patient experiences of recovery after heart valve replacement: Suffering weakness, struggling to resume normality. Biomedical Central, 12(23), 1-8. doi:

10.1186/1472-6955-12-23. Doi.org/10.1186/1472-6955-12-23

Biese, K., LaMantia, M., Shofer, F., McCall, B., Roberts, E., Stearns, S. C., . . . BusbyWhitehead, J. (2014). A randomized trial exploring the effect of a telephone call follow-up on care plan compliance among older adults discharged home from the emergency department. Academic Emergency Medicine, 21, 188-195. http://doi.org/10.1111/aem.12308

Bontje, P., Asaba, E., Tamura, Y., \& Josephsson, S. (2012). Japanese older adults’ perspectives on resuming daily life during hospitalization and after returning home. Occupational Therapy International, 19(2), 98-107. https://doiorg.sandiego.idm.oclc.org/10.1002/oti.329

Bowles, K. H., Chittams, J., Heil, E., Topaz, M., Rickard, K., Bhasker, M... \& Hanlon, A. L. (2015), Successful electronic implementation of discharge referral decision support has a positive impact on 30- and 60-day readmissions. Research in Nursing \& Health, 38, 102-114. doi:10.1002/nur.21643 
Brooten, G., Kumar, S., Brown, L., Butts, R., Finkler, S., Bakewell-Sachs, S. . . Deliviria-Papadopoulos, M. (1986). A randomized clinical trial of early hospital discharge and home follow-up of very-low birth-weight infants. New England Journal of Medicine. 315, 934-939. doi: 10.1056/NEJM19861009151505

Brooten, D., Naylor, M. D., York, R., Brown, L., Roncoli, M., Hollingsworth, A. . . Jacobson, B. (1995). Effects of nurse specialist transitional care on patient outcomes and cost: Results of five randomized trials. American Journal of Managed Care, 1(1) 45-51.

Bryant, A., \& Charmaz, K. (2007). The Sage handbook of grounded theory. Thousand Oaks, CA: Sage.

Center for Disease Control and Prevention. (2015). At a glance 2015, healthy aging. Helping older Americans achieve healthy and high-quality lives. Retrieved from https://www.cdc.gov/chronicdisease/resources/publications/aag/healthy-aging.htm

Centers for Medicare and Medicaid Services. (n.d.a). 30-day unplanned readmission and death measures. Retrieved from http://www.medicare.gov/hospitalcompare/data/30-day-measures.html

Centers for Medicare and Medicaid Services. (n.d.b). Measures and current data collection periods. Retrieved from https://www.medicare.gov/hospitalcompare/Data/Data-Updated.html\#

Centers for Medicare and Medicaid Services. (2015a). Hospital inpatient prospective payments system for acute care hospitals and the long-term care hospital prospective payment system policy changes and fiscal year 2016 rates. Federal Register. Retrieved from https://federalregister.gov/a/2015-19049 
Centers for Medicare and Medicaid Services. (2015b). IMPACT Act of 2014 \& cross settling measures. Retrieved from www.cms.gov/Medicare/Quality-InitativesPatient-Assessment-Instruments/Post-Acute-Care0Qualtiy-Initiatives?IMPACTAct-0f-2014

Centers for Medicare and Medicaid Services. (2017). Medicare and Medicaid program: Conditions of participation for home health agencies. Retrieved from https://www.federalregister.gov/documents/2017/01/13/2017-00283/medicareand-medicaid-program-conditions-of-participation-for-home-health-agencies

Centers for Medicare and Medicaid Services. (2019a) Condition Categories. Retrieved from https://www.ccwdata.org/web/guest/condition-categories

Centers for Medicare and Medicaid Services. (2019b). Hospital Readmissions Reduction Program (HRRP). Available at https://www.cms.gov/medicare/medicare-fee-forservice-payment/acuteinpatientpps/readmissions-reduction-program.html

Charmaz, K. (2001). Grounded theory. In: R. M. Emerson (Ed.). Contemporary field research: Perspectives and formulations (2nd ed., pp.242-243). Prospect Heights, IL: Waveland Press.

Charmaz, K. (2006). Constructing grounded theory: A practical guide through qualitative analysis (4th ed.). Thousand Oaks, CA: Sage.

Charmaz, K. (2012). The power and potential of grounded theory. Medical Sociology Online, 6(3), 2-15. Retrieved from http://www.medicalsociologyonline.org/resources/MSo-\&-MSNArchive/MSo_v.6/MSo-Volume-6-Issue-3.pdf 
Charmaz, K. (2014). Constructing grounded theory (2 ed., pp. 1-4). Thousand Oaks, CA: Sage

Christians, C. G. (2011). Ethics and politics in qualitative research. In N. K. Denzin, \& Y. S. Lincoln (Eds.). The Sage handbook of qualitative research (pp. 61-80). Thousand Oaks, CA: Sage.

Cienki, J. J., Guerrera, A. D., Rose-Steed, N., Kubo, E. N., \& Baumann, B. M. (2013). Impact of an electronic medical record system on emergency department discharge instructions for patients with hypertension. Postgraduate Medicine, 125(5), 59-66. doi:10.3810/pgm.2013.09.2702

Cobley, C. S., Fisher, R. J., Chouliara, N., Kerr, M., \& Walker, M. F. (2013). A qualitative study exploring patients' and carers' experience of early supported discharge services after stroke. Clinical Rehabilitation, 27, 750-757. doi:10.1177/0269215512474030

Coleman, E., Chugh, A., Williams, M., Grigsby, J., Glasheen, J., McKenzie, M., \& Min, S. J. (2013). Understanding and execution of discharge instructions. Sage Journals, 28, 383-391.

Cohen, D. (2015). Effect of the exclusion of behavioral health from health information technology (HIT) legislation on the future of integrated health care. Journal of Behavioral Health Services \& Research, 42, 534-539. https://doiorg.sandiego.idm.oclc.org/10.1007/s11414-014-9407-X

Cornu, P., Steurbaut, S., Leysen, T., De Baere, E., Ligneel, C., Mets, T., \& Dupont, A. G. (2012). Discrepancies in medication information for the primary care physician 
and the geriatric patient at discharge. Annals of Pharmacotherapy, 46, 983-991. doi.org/10.1345/aph.1r022

Costantino, M. E., Frey, B., Hall, B., \& Painter, P. (2013). The influence of a postdischarge intervention on reducing hospital readmissions in a Medicare population. Population Health Management, 16, 310-316.

Creswell, J. W. (2008). Educational research: Planning, conducting, and evaluating quantitative and qualitative research (3rd ed.). Upper Saddle River, NJ: Pearson Education.

Creswell, J. W. (2013). Philosophical assumptions and interpretive frameworks. (3rd ed., pp. 15-41). Thousand Oaks, CA: Sage.

Denzin, N. K., \& Lincoln, Y. S. (2011). The Sage handbook of qualitative research (4th ed.). Thousand Oaks, CA: Sage.

Dudas, V., Bookwalter, T., Kerr, K. M., \& Pantilat, S. Z. (2001). The impact of follow-up telephone calls to patients after hospitalization. American Journal Medicine, $111(9 \mathrm{~B}), 26 \mathrm{~S}$.

Eaton, C K. (2018). Social workers, nurses, or both: Who is primarily responsible for hospital discharge planning with older adults? Social Work in Health Care, 51, 851-863.

Enguidanos, S., Coulourides Kogan, A. M., Schreibeis-Baum, H., Lendon, J., \& Lorenz, K. (2015). 'Because I was sick': Seriously ill veterans' perspectives on reason for 30-day readmissions. Journal of the American Geriatrics Society, 63, 537-542. doi:10.1111/jgs.13238 
Erdem, E., Prada, S. I., \& Haffe, S. C. (2013) Medicare payments: How much do chronic conditions matter? Medicare \& Medicaid Research Review, 3(2), 3-15. doi: http://dx.doi.org/10.5600/mmrr.003.02.b02

Falvey, J., Burke, R., Malone, D., Ridgeway, K. J., McManus, B., \& Stevens-Lapsley, J. E. (2016). Role of physical therapists in reducing hospital readmission: Optimizing outcomes for older adults during care transitions from hospital to community. Physical Therapy, 96(8), 1125 - 1134.

Doi.org/10.2522/ptj.20150526.

Flynn, A. J., \& Stevenson, J. G. (2018). The future of data, analytics, and information technology. American Journal of Health-System Pharmacy, 75(2), 31-34.

Franklin, M. M., \& McCoy, M. A. (2017). The transition of care from hospital to home for patients with hypertension. The Nurse Practitioner, 42(2), 12-18. http:// doi.org/10.1097/01.NPR.0000511701.94615.4f

Glaser, B. G., \& Strauss, A. L. (1967). The discovery of grounded theory: Strategies for qualitative research. New Brunswick, NJ: Rutgers University Press.

Gorina, Y., Pratt, L., Kramarow, E. A., \& Elgaddal, N. (2015). Hospitalization, readmission, and death experience of noninstitutionalized Medicare fee-forservice beneficiaries aged 65 and over. National Health Statistics Reports. (Report No. 84.) Retrieved from www.cdc.gov/nchs/data/nhsr/nhsr084

Grover, S. (2005). Shaping effective communication skills and therapeutic relationships at work. AAOHN Journal, 53, 177-182. 
Harris, J. R., \& Wallace, R. B. (2012). The Institute of Medicine's new report on living well with chronic illness. Preventing Chronic Disease. 9, 120-126.

doi: http://dx.doi.org/10.5888/pcd9.120126

He, W., Goodkind, D., \& Kowal P. (2016). An aging world: 2015. (Report No. P95/161). Retrieved from https://www.census.gov/content/dam/Census/library/publications/2016/demo/p9516-1.pdf

Healthcare Cost and Utilization Project. (2009). Facts and figures: Statistics on hospitalbased care in the United States. Rockville, MD: Agency for Healthcare Research and Quality. Retrieved from http:// www.hcupus.ahrq.gov/reports/factsandfigures/2009/pdfs/FF_report_2009.pdf

Higginbottom, L. G. (2013). The roots and development of constructivist grounded theory. Nurse Researcher, 21(5), 8-13.

Hines, A. L., Barrett, M. L., Jiang, H. J., \& Steiner, C. A. (2014). Conditions with the largest number of adult hospital readmissions by payer, 2011. (HCUP Statistical Brief 172). Rockville, MD: Agency for Healthcare Research and Quality. Retrieved from http:// www.hcup-us.ahrq.gov/reports/statbriefs/sb172Conditions-Readmissions-Payer.pdf

Holland, D., \& Hemann, M. A. (2011). Standardizing hospital discharge planning at the Mayo Clinic. The Joint Commission Journal on Quality and Patient Safety, 37(1), 29-30. http:// doi.org/10.1016/S1553-7250(11)37004-3 
Holland, D. E., Mistiaen, D. E., \& Bowles, K. H. (2011). Problems and unmet needs of patients discharged "home to self-care." Professional Case Management, 16, 249252.

Holloway, I., \& Wheeler, S. (2010). Qualitative research in nursing and healthcare (3rd ed.). Hoboken, NJ: John Wiley \& Sons.

Jencks, S. F., Williams, M. V., \& Coleman, E. (2009). Rehospitalizations among patients in the Medicare fee-for-service program. New England Journal of Medicine, 360, 1418-1428. doi: 10.1056/NEJMsa0803563

Jeungok C. (2017). Effect of pictograph-based discharge instructions on older adults' comprehension and recall. Research in Gerontological Nursing, 10(2), 66-71. https://doi-org.sandiego.idm.oclc.org/10.3928/19404921-20150513-05

Karlsson, V., Bergbom, I., Ringdal, M., \& Jonsson, A. (2015). After discharge home: a qualitative analysis of older ICU patients' experience and care needs. Caring Sciences, 30(4), 749-756. Doi.org/10.1111/scs.12301

Keenan, P. S., Normand, S. L. T., Lin, Z., Drye, E. E., Bhat, K. R., Ross, J. S, . .. Krumholz, H. M. (2008). An administrative claim measure suitable for profiling hospital performance on the basis of 30-day all-cause readmission rates among patients with heart failure. Circulation: Cardiovascular Quality and Outcomes, 1(1). doi:10.1161/circoutcomes.108.802686

Kirkman, S. M., Briscoe, V. J., Clark, N., Florez, H., Haas, L. B., Halter, J. B., ...Swift, C. S. (2019). Access the 2019 standard of care guidelines: Diabetes in the older adult. Diabetes Care, 35, 2650-2664. Retrieved from http://care.diabetesjournals.org/content/35/12/2650.full-text.pdf. 
Kwok, T., Lee, J., Woo, J., Lee, D., \& Griffith, S. (2008). A randomized controlled trial of a community nurse-supported hospital discharge programme in older patients with chronic heart failure. Journal of Clinical Nursing, 17(1), 109-117. doi:10.1111/j.1365-2702.2007.01978.x

Logan, H., Guo, Y., Dodd, V. J., Muller, K., \& Riley, J., III. (2013). The burden of chronic diseases in a rural North Florida sample. BMC Public Health, 13, 906915. doi:10.1186/1471-2458-13-906

Markham, A., \& Buchanan, E. (2012). Ethical decisions-making and internet research. Retrieved from http://www.aoir.org/reports/ethics2.pdf

McCann, T., \& Clark, E. (2003). Grounded theory in nursing research: Part 2 -- critique. Nurse Researcher, 11(2), 19-28.

National Center for Health Statistics. (2014). Publications and information products, health, United States, special feature on adults aged 55-64. Retrieved from https://www.cdc.gov/nchs/data/hus/hus14.pdf

National Center for Health Statistics. (2016). National health interview survey. Retrieved from http://www.cdc.gov/nchs/nhis/2018_quest_redesign.htm

Naylor, M. D., Brooten, D., Campbell, R., Jacobsen, B. S., Mezey, M. D., Pauly, M. V., J. \& Schwartz, S. (1999). Comprehensive discharge planning and home follow-up of hospitalized elders. A randomized clinical trial. JAMA, 281, 613-620. doi:10.1001/jama.281.7.613

Naylor, M. D., Brooten, D., Campbell, R., Maislin, G., McCauley, K. M., \& Schwartz, S. (2004). Transitional care of older adults hospitalized with heart failure: A 
randomized, controlled trial. Journal of the American Geriatrics Society, 52, 675684. doi: 10.1111/j.1532-5415.2004.52202.x

Naylor, M., Kurtzman, E., \& Pauly, M. (2009a). Managing the transition from the hospital. Managed Care, 23(6), 27-30.

Naylor, M., Kurtzman, E., \& Pauly, M. (2009b). Transitions of elders between long-term care and hospitals. Policy, Politics, \& Nursing, 10(3), 187-194.

Neiterman, E., Wodchis, W., \& Bourgeault, I. L. (2015). Experiences of older adults in transition from hospital to community. Canadian Journal on Aging, 34(1), 90-99. Doi.org/10.1017/S)714980814000518.

Newman, B. (2007). Challenging convention: Symbolic interaction and grounded theory. Collegian. 15, 103-107.

Office of Disease Prevention and Health Promotion. (2017). Older adults, Retrieved from https://www.healthypeople.gov/2020/topics-objectives/topic/older-adults

Oliver, T. R., Lee, P. R., \& Lipton, H. (2004). A political history of Medicare and prescription drug coverage. Journal of the American Society on Aging, 82(2), 283354. doi: 10.1111/j.0887-378X.2004.00311.x

Ormston, R., Spencer, L., Barnard, M., \& Snape, D. (2013). The foundations of qualitative research. In J. Ritchie, J. Lewis, C. McNaughton-Nicholls, \& R. Ormston (Eds.). Qualitative research practice: A guide for social science students and researcher. (pp. 1-25). Thousand Oaks, CA: Sage.

Oxford Academy. (2015). Living well with chronic illness: A call for public health action. Military Medicine, 180(5), 485-487, https://doi.org/10.7205/MILMEDD-15-00034 
Patient Protection and Affordable Care Act. 42 U.S.C. $§ 18001$ et seq. (2010). Retrieved from http:// https://www.gpo.gov/fdsys/pkg/PLAW-111publ148/pdf/PLAW111publ148.pdf

Peter, D., Robinson, P., Jordan, M., Lawrence, S., Casey, K., \& Salas-Lopez, D. (2015). Reducing readmissions using teach-back. Journal of Nursing Administration, 45(1), 35-42. doi.org/10.1097/NNA.0000000000000155

Phatak, A., Prusi, R., Ward, B., Hansen, L. O., Williams, M. V., Vetter, E., Chapman, N., Postelnick, M. (2016). Impact of pharmacist involvement in the transitional care of high-risk patients through medication reconciliation, medication education, and post discharge call-backs (IPITCH Study). Journal Hospital Medicine, 11(1), 3944.

Robert Wood Johnson Foundation. (2013). The revolving door: A report on U.S. hospital readmissions. Retrieved from http://www.rwjf.org/content/dam/farm/reports/reports/2013/rwjf404178

Saldana, J. (2016). The coding manual for qualitative researcher. (3rd ed.). Thousand Oaks, CA: Sage.

Shinkman, R. (2014, April 20). Readmissions lead to $\$ 41.3 \mathrm{~B}$ in additional hospital costs. Retrieved from www.fiercehealthcare.com/finance/readmissions-lead-to-41-3b$\underline{\text { additional-hospital-costs }}$

Taule, T., Strand, Skouen, L. I., and Raheim, J. S., \& Målfrid Råheim, P. (2015). Striving for a life worth living: Stroke survivors' experiences of home rehabilitation. Caring Sciences, 29, 651-661. doi: 10.1111/scs.12193 
Tavares, M. M, Gomes, A. M. T, Barbosa, D. J., Cruz da Rocha, J. C., Rocha Bernardes, M. M. R. \& Thiengo, P. C. S. D. (2018). Spirituality and religiosity in the daily routine of hospital nursing. Journal of Nursing UFPE / Revista de Enfermagem UFPE, 12(4), 1097-1102. https://doi-org.sandiego.idm.oclc.org/10.5205/1981$\underline{8963-v 12 i 4 a 235018 p 1097-1102-2018}$

The Joint Commission. (2012). Transitions of care: The need for a more effective approach to continuing patient care. Retrieved from https://www.jointcommission.org/assets/1/18/Hot_Topics_Transitions_of_Care.p $\underline{\mathrm{df}}$

The Joint Commission. (2018). About the joint commission. Retrieved from https://www.jointcommission.org/about_us/about the joint_commission_main.as $\underline{\mathrm{px}}$

The Joint Commission. (2019). National patient safety goals effective january 2019. Retrieved from https://www.jointcommission.org/assets/1/6/NPSG_Chapter_HAP_Jan2019.pdf

The Joint Commission Center for of Transforming care. (2018). Hand-off communications targeted solutions tool. Retrieved from https://www.centerfortransforminghealthcare.org/tst_hoc.aspx

Urquhart, C., \& Walter, F. (2006). Grounded theory method: The researcher as a blank slate and other myths. International Conference on Information System 2006 Proceedings, 31. Retrieved from http://aisel.aisnet.org/cgi/viewcontent.cgi?article $=1152 \&$ context $=\mathrm{icis} 2006$ 
U. S. Census Bureau. (2011). The older population: 2010. 2010 Census brief. Retrieved from https://www.census.gov/prod/cen2010/briefs/c2010br-09.pdf

U. S. Census Bureau. (2014). The baby boom cohort in the United States: 2010 to 2060.

Retrieved from https://www.census.gov/prod/2014pubs/p25-1141.pdf

U. S. Census Bureau. (2016). QuickFacts United States. Retrieved from http://www.census.gov/quickfacts/table

U. S. Department of Health and Human Services. (2010). Multiple chronic conditions: A strategic framework. Optimum health and quality of life for individuals with multiple chronic conditions. Retrieved from https://www.hhs.gov/ash/initiatives/mcc/mcc_framework.pdf

U. S. Department of Health and Human Services \& U. S. Department of Justice. (2016). The Affordable Care Act and fighting fraud. Retrieved from https://www.stopmedicarefraud.gov/aboutfraud/aca-fraud/index.html

U. S. Food and Drug Administration. (2014). Clinical trials and human subject protection. Retrieved from http://www.fda.gov/scienceresearch/specialtopics/runningclinicaltrials/default.ht $\underline{\mathrm{m}}$

Werner, C. (2011). The older population: 2010. 2010 census briefs. Retrieved from https://www.census.gov/prod/cen2010/briefs/c2010br-09.pdf

Wetz, F. J., Charmaz, K., McMullen, L. M., Josselson, R., Anderson, R., \& McSpadden, E. (2011). Five ways of doing qualitative analysis: Phenomenological psychology, grounded theory, discourse analysis, narrative research, and intuitive inquiry. New York, NY: Guilford Press. 
Wilson, K. (2018). Mobile cell phone technology puts the future of health care in our hands. CMAJ: Canadian Medical Association Journal, 190, E378-E379.

\section{doi.org/10.1503/cmaj.180269}

Zhang, D. J., Gurvich, I., Van Mieghem, J. A., Park, E., Young, R. S., \& Williams, M. V. (2014). Hospital readmissions reduction programs: An economic and operational analysis. Management Science, 62(11), 3085-3391. doi.org/10.1287/mnsc.2015.2280

Appendix A

Interviewing questions reframed

Patient in the dyad will be asked these questions in separate interviews. Initial questions will include:

1. At what point during your hospital stay did you feel you were being prepared to go home (be discharged)? how did you know you were going home?

2. During the discharge process, what went well? Is there anything you can think of that did not go well? Did you experience any problems planning to leave the hospital?

\section{What did the nurse tell you to do at? Is a nurse coming to your home?}

4. Now that you are home, how is everything going?

\section{Any new or changed medications? Did your diet change? Any problems?}

How are you handling these things: this question will be patient specific based on the discharge instructions received [i.e.: wound, catheter, etc.]) 
6. Have you read the discharge instructions since arriving home? May I take a look at the discharge instructions. If so, how have the discharge instructions been helpful?

7. Now that you are home, have the discharge instructions been helpful, anything you disagree with or will do differently? What have you done differently and why? (Patient and Caregiver)

8. The hospital discharge instructions indicate you should follow up with the doctor. Have you scheduled an appointment yet? (confirmed the appointment was made) Do you have any concerns with transportation, financial issues, or other concerns/issues you would like to share that have not been brought up today?

9. Did you see your medical record while in the hospital?

10. May I take a picture where you stored your discharge instructions that you were given in the hospital and any that you have been given since you came home? The investigator elected not to take a picture since confidentiality could not be assured.

To end the interview, summary questions will be asked to allow the participants to reflect or elaborate on previous information discussed (Charmaz, 2014). These questions will include:

4. Is there anything else you can think of that will help me understand how you used or didn't use the discharge instructions?

5. Is there anything else you would like to share?

6. Do you have any questions you would like to ask me?

Informational interviews seek to obtain the following information: 
1. Participants characteristics such as race, ethnicity, gender, age, education, profession, occupation, income level, and marital status were collected.

2. Hospital discharge date.

3. The process by which both participants in the dyad obtained the discharge instructions.

4. Roles of health professionals who were involved with providing discharge instructions, such as nurse, pharmacist, physician, discharge planner, and others, if known. No names or personal identifying information about health care professionals were collected.

5. Whether the patient or caregiver had reviewed the electronic medical record while hospitalized.

\section{General questions such as how things are going now that you are home}

instead of: Perceived barriers and facilitators to implementation of discharge instructions. 


\section{Appendix B}

Memo writing

Field notes

Filipino family-extended 3 generation

While sitting outside the home I watched people coming and going from the home.

The home seems very strange-she informed me she takes in homeless people.

She went around introducing me the anyone that came into the dining room/kitchen.

She was very friendly, very talkative

People continued to walk through the house back and forth either to exit the home or to go in the back of the house. One man, skinny, pale, (she told me he has cancer) would come into the area, stand around and then leave. Then he would return, stand around, pouring himself some juice and then leave. The participants would look toward him with her peripheral vision while continuing her conversation. She talks a lot about her life volunteering with gleam. I had to keep my back against the wall, there were strange people coming and going. She described herself as the matriarch of the house. People coming around shows her respect. Her son has passed, and her daughter-in-law lives with her... like a daughter. The DTI shows her a lot of love. The DIL is tearful sharing how much she missed the patient while she was in the hospital. 
She has fed the homeless for 25 years. The house, except for the front room, was filled with many donations. The dining room was filled with bread donation. She had many cacti and plants. Her life revolves around feeding the poor/homeless.

She is so happy to be home. She gave me a tour of her garage filled with all kinds of items. Even the back yard was filled with donated items. Her front yard is well manicured, another hobby that she enjoys. You can tell her she has lived in the home for years. She is ready to cook a pot of stew tonight to feed the homeless tomorrow. After redirecting to share her hospital experience and returning home always directed her back to her life before the hospitalization.

She is ready to move on with her life... 


\section{Appendix C}

\section{USD IRB}

Oct 17, 2017 8:59 AM PDT

Brenda Miller

Hahn School of Nursing \& Health Science

Re: Expedited - Initial - IRB-2018-62, Older Adults' and Informal Caregivers'

Implementation of Discharge Instructions Following an Acute Care Hospital Stay

Dear Brenda Miller:

The Institutional Review Board has rendered the decision below for IRB-2018-62, Older Adults' and Informal Caregivers' Implementation of Discharge Instructions Following an Acute Care Hospital Stay.

Decision: Approved

Selected Category: 5. Research involving materials (data, documents, records, or specimens) that have been collected, or will be collected solely for nonresearch purposes (such as medical treatment or diagnosis).

7. Research on individual or group characteristics or behavior (including, but not limited to, research on perception, cognition, motivation, identity, language, communication, cultural beliefs or practices, and social behavior) or research employing survey, interview, oral history, focus group, program evaluation, human factors evaluation, or quality assurance methodologies.

Findings: None

Research Notes:

Internal Notes:

Note: We send IRB correspondence regarding student research to the faculty advisor, who bears the ultimate responsibility for the conduct of the research. We request that the faculty advisor share this correspondence with the student investigator.

The next deadline for submitting project proposals to the Provost's Office for full review is $N / A$. You may submit a project proposal for expedited or exempt review at any time.

Sincerely,

Dr. Thomas R. Herrinton

Administrator, Institutional Review Board

Office of the Vice President and Provost

Hughes Administration Center, Room 214

5998 Alcalá Park, San Diego, CA $92110-2492$

Phone (619) 260-4553 $・ F a x \underline{\text { (619) 260-2210 }}$ www.sandiego.edu 